\title{
A network pharmacology-based approach to explore the active ingredients and molecular mechanism of Lei-gong-gen formula granule on a spontaneously hypertensive rat model
}

\author{
Qiaofeng Li ${ }^{1,2 \dagger}$, Taijin Lan ${ }^{3 \dagger}$, Songhua He ${ }^{4 \dagger}$, Weiwei Chen ${ }^{5,6}$, Xiaolan Li ${ }^{1,2}$, Weiquan Zhang ${ }^{1,2}$, Ying Liu $^{2,7}$,
} Qiuping Zhang ${ }^{2,8}$, Xin Chen ${ }^{1,2}$, Yaoyao Han ${ }^{1,2}$, Zhiheng Su ${ }^{1^{*}}$, Dan Zhu ${ }^{1 *}$ and Hongwei Guo ${ }^{1,2,5^{*}}$

\begin{abstract}
Background: Lei-gong-gen formula granule (LFG) is a folk prescription derived from Zhuang nationality, the largest ethnic minority among 56 nationalities in China. It consists of three herbs, namely Eclipta prostrata (L.) L., Smilax glabra Roxb, and Centella asiatica (L.) Urb. It has been widely used as health protection tea for hundreds of years to prevent hypertension in Guangxi Zhuang Autonomous Region. The purpose of this study is to validate the antihypertensive effect of LFG on the spontaneously hypertensive rat (SHR) model, and to further identify the effective components and anti-hypertension mechanism of LFG.
\end{abstract}

Methods: The effects of LFG on blood pressure, body weight, and heart rate were investigated in vivo using the SHR model. The levels of NO, ANG II, and ET-1 in the serum were measured, and pathological changes in the heart were examined by H\&E staining. The main active components of LFG, their corresponding targets, and hypertension associated pathways were discerned through network pharmacology analysis based on the Traditional Chinese Medicine Systems Pharmacology (TCMSP), Traditional Chinese Medicine Integrated Database (TCMID), and the Bioinformatics Analysis Tool for Molecular Mechanism of Traditional Chinese Medicine (BATMAN-TCM). Then the predicted results were further verified by molecular biology experiments such as RT-qPCR and western blot. Additionally, the potential active compounds were predicted by molecular docking technology, and the chemical constituents of LFG were analyzed and identified by UPLC-QTOF/MS technology. Finally, an in vitro assay was performed to investigate the protective effects of potential active compounds against hydrogen peroxide $\left(\mathrm{H}_{2} \mathrm{O}_{2}\right)$ induced oxidative damage in human umbilical vein endothelial cells (HUVEC).

Results: LFG could effectively reduce blood pressure and increase serum NO content in SHR model. Histological results showed that LFG could ameliorate pathological changes such as cardiac hypertrophy and interstitial inflammation. From network pharmacology analysis, 53 candidate active compounds of LFG were collected, which linked to 765 potential targets, and 828 hypertension associated targets were retrieved, from which 12 overlapped targets

\footnotetext{
*Correspondence: suzhiheng915@126.com; zdgxmu2006@163.com; hongweiguo@gxmu.edu.cn

${ }^{\dagger}$ Qiaofeng Li, Taijin Lan and Songhua He contributed equally to this work ${ }^{1}$ Guangxi Key Laboratory of Bioactive Molecules Research and Evaluation \& College of Pharmacy, Guangxi Medical University, 22 Shuangyong Road, Nanning 530021, China

Full list of author information is available at the end of the article
} permits use, sharing, adaptation, distribution and reproduction in any medium or format, as long as you give appropriate credit to the original author(s) and the source, provide a link to the Creative Commons licence, and indicate if changes were made. The images or other third party material in this article are included in the article's Creative Commons licence, unless indicated otherwise in a credit line to the material. If material is not included in the article's Creative Commons licence and your intended use is not permitted by statutory regulation or exceeds the permitted use, you will need to obtain permission directly from the copyright holder. To view a copy of this licence, visit http://creativecommons.org/licenses/by/4.0/. The Creative Commons Public Domain Dedication waiver (http://creativeco mmons.org/publicdomain/zero/1.0/) applies to the data made available in this article, unless otherwise stated in a credit line to the data. 
both related to candidate active compounds from LFG and hypertension were screened and used as the potential targets of LFG on antihypertensive effect. The molecular biology experiments of the 12 overlapped targets showed that LFG could upregulate the mRNA and protein expressions of NOS3 and proto-oncogene tyrosine-protein kinase SRC (SRC) in the thoracic aorta. Pathway enrichment analysis showed that the PI3K-AKT signaling pathway was closely related to the expression of NOS3 and SRC. Moreover, western blot results showed that LFG significantly increased the protein expression levels of PI3K and phosphorylated AKT in SHR model, suggesting that LFG may active the PI3K-AKT signaling pathway to decrease hypertension. Molecular docking study further supported that p-hydroxybenzoic acid, cedar acid, shikimic acid, salicylic acid, nicotinic acid, linalool, and histidine can be well binding with NOS3, SRC, PI3K, and AKT. UPLC-QTOF/MS analysis confirmed that p-hydroxybenzoic acid, shikimic acid, salicylic acid, and nicotinic acid existed in LFG. Pre-treatment of HUVEC with nicotinic acid could alleviate the effect on cell viability induced by $\mathrm{H}_{2} \mathrm{O}_{2}$ and increase the NO level in cell supernatants.

Conclusions: LFG can reduce the blood pressure in SHR model, which might be attributed to increasing the NO level in serum for promoting vasodilation via upregulating SRC expression level and activating the PI3K-AKT-NOS3 signaling pathway. Nicotinic acid might be the potential compound for LFG antihypertensive effect.

Keywords: Centella asiatica (L.) Urb., Eclipta prostrata (L.) L., Smilax glabra Roxb., Hypertension, Network pharmacology

\section{Introduction}

Hypertension is one of the most common cardiovascular diseases, which can cause damage to the heart, brain, kidney, and other important organs [1]. It is an important risk factor for the death of the global population and poses a serious threat to patient safety and quality of care. In China, large-scale population surveys of hypertension have reported a rapidly increasing prevalence of hypertension, from $5.1 \%$ to 1959 to $27.8 \%$ in 2014 [2]. In Europe, Canada, and the United States, the prevalence varied from 27 to $55 \%$ [3]. Hypertension is a chronic disease, and there is no complete cure for high blood pressure. Currently, drug treatment is mainly used to control blood pressure and bring it down to a normal range in clinical practice. Although the existing antihypertensive drugs can effectively control blood pressure in the short term, it is prone to develop adverse effects for long term medication, which greatly affects their treatment compliance [4]. Therefore, the development of drugs, which can effectively lower blood pressure with fewer adverse reactions, is still the current research direction. Traditional Chinese Medicine (TCM) has accumulated much experience in the treatment of hypertension [5]. TCM has the characteristics of multi-component, multi-target, and multi-pathways, especially has a certain effect in improving the complications of hypertension [6]. Thus, screening high-efficiency antihypertensive drugs with fewer side effects based on Chinese medicine formula has attracted considerable attention.

Lei-gong-gen formula granule (LFG) is an effective antihypertensive traditional Chinese folk prescription, and residents of Guangxi Zhuang Autonomous Region have soaked it in wine or used as tea for many years [7]. Epidemiological data showed that the prevalence of hypertension among residents was $13.70 \%$, which was significantly lower than the national average (25.2\%) [8]. It is speculated that the lower incidence of hypertension of the local people may be related to their long-term use of this formula. LFG is composed of three herbs, containing Centella asiatica (L.) Urb. (Ji-xue-cao, also known as Lei-gong-gen in Chinese medicine), Eclipta prostrata (L.) L. (Mo-han-lian), and Smilax glabra Roxb. (Tu-fuling). Centella asiatica (L.) Urb. is a tropical medicinal plant belonging to the family Apiaceae (Umbelliferae). It is widely distributed in many regions of the world, especially in Asian countries, including India, China, Indonesia and Nepal. Centella asiatica (L.) Urb. was reported to exhibit cardioprotective, antihypertensive, antioxidant, and anti-inflammatory activities [9]. Recent clinical study from Indonesia has shown that gotu kola (Centella asiatica L.) tea can decrease blood pressure of hypertension patients [10]. Asiatic acid could reduce blood pressure and improve vascular function by restoring the expression of endothelial NO synthase (eNOS) and p47phox, thereby alleviating cardiovascular remodeling by restoring iNOS/eNOS expression in L-NAME hypertensive rats [11]. Eclipta prostrata (L.) L. is an annual herb of the Asteraceae family, native to China, Japan, and India [12]. Eclipta prostrata (L.) L. was reported to have significant pharmacological features, such as antioxidant, anti-inflammatory, and hypotensive activities [13]. Smilax glabra Roxb. is the rhizome of the Liliaceae plant [14]. Pharmacological studies demonstrated that the flavonoids from Smilax glabra Roxb. exhibited anti-cardiac hypertrophy and anti-hypertensive effects on renovascular hypertension rats by regulating atrial natriuretic peptide levels [15].

Chinese herbal formulae contain a large number of compounds and it is too complex to be analyzed by traditional experimental methods based on the paradigm of 
"One gene, one drug, one disease" [16]. Along with the rapid development of bioinformatics, a newly emerging network pharmacology that uses a mathematical and computable representation of various connections between herbal formulae and diseases has been proposed [17]. The holistic philosophy is the main feature of TCM, which meets the critical idea of network pharmacology [18]. Focusing on studying drugs, network pharmacology provides new ideas, especially for TCM research, which is based on a complex system. It has provided new scientific and technological support for the rational clinical use of drugs and drug development [19]. Accumulating evidence shows that network pharmacology can clarify the potential mechanisms of multi-component and multi-target agents by analyzing various complex and multi-level interaction networks [20].

In this study, the active ingredients, corresponding targets, and pharmacological mechanisms of LFG antihypertensive effect were investigated by integrating network pharmacology prediction and molecular biology experimental validations. As shown in Fig. 1, the entire study consists of three steps. Step 1: animal experiments. The spontaneously hypertensive rat (SHR) model was used to observe the antihypertensive effect of LFG. Step 2: network pharmacology analysis. The effective ingredients, corresponding targets, and hypertension associated pathways were predicted through public databases. The protein-protein interaction (PPI) networks of LFG-related targets and hypertension-related targets were constructed, and the core targets were identified through topological analysis. Step 3: experimental verification. Based on the SHR model, the predicted results were verified by molecular biology methods such as RTqPCR and western blot. The potential active ingredients were predicted by molecular docking technology, and the LFG chemical constituents were analyzed and identified by Ultra performance liquid chromatography/quadrupole time-of-flight mass spectrometry (UPLC-QTOF/ MS) technology. The ingredients which confirmed by UPLC-QTOF/MS were used to investigate the protective

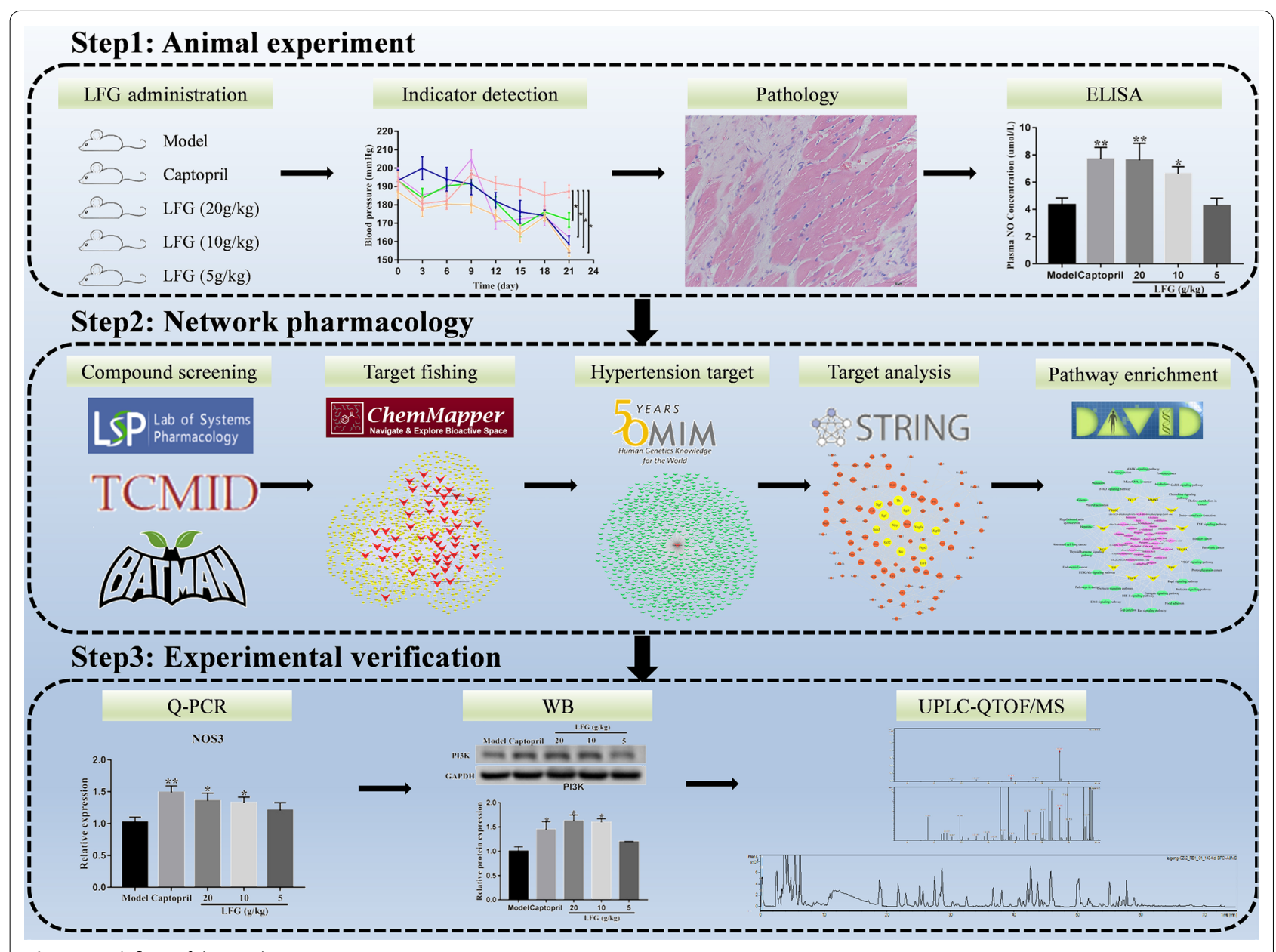

Fig. 1 Work flow of the study 
effects against $\mathrm{H}_{2} \mathrm{O}_{2}$ induced oxidative damage in human umbilical vein endothelial cells (HUVEC). The findings of this study may contribute to the clarification of active ingredients and underlying mechanisms of LFG and provide an accurate and reasonable reference for the clinical application of LFG.

\section{Materials and methods}

\section{Drugs and reagents}

Lei-gong-gen formula granule (LFG) was purchased from Guangxi Institute of Chinese Medicine and Pharmaceutical Science (Guangxi, China, lot No. 20,170,210). The authentication of three dried herbal drugs (Centella asiatica (L.) Urb., Eclipta prostrata (L.) L., Smilax glabra Roxb.) has been specified, and the preparation of LFG was shown in our previous research [21, 22]. Captopril was obtained from Teyi Pharmaceutical Group Co., Ltd (Guangdong, China, lot No. 20,170,501). p-hydroxybenzoic acid (lot No. H108509), shikimic acid (lot No. S107143), salicylic acid (lot No. S118533), and nicotinic acid (lot No. N103654) were purchased from Aladdin Reagent Co., Ltd. (Shanghai, China).

The Nitric oxide (NO) assay kit was obtained from Nanjing Jiancheng Bioengineering Institute (Nanjing, China, Cat. A013-2 and A012-1). Rat angiotensin II (ANG II, Cat. CSB-E04494r) and rat endothelin 1 (ET-1, Cat. CSB-E06979r) ELISA kits were obtained from CUSABIO (Wuhan, China). Trizol reagent (Cat. 15,596,026), cDNA Reverse Transcription Kit (Cat. 4368814), SYBR Green Master Mix (Cat. A25742), Pierce Protease and Phosphatase Inhibitor Mini Tablets (Cat. A32961), RIPA buffer (Cat. 89900), Prestained Protein Ladder (Cat. 26616), Tween 20 (Cat. 85113), Chemiluminescent Substrate (Cat. 24580) were purchased from Thermo Fisher Scientific (Waltham, USA). The Bicinchoninic acid (BCA) Protein Assay Kit (No. P0011) was purchased from Beyotime Biotechnology Co., Ltd. (Shanghai, China).

GAPDH (14C10) Rabbit mAb (Cat. 2118), SRC (36D10) Rabbit mAb (Cat. 2109), PI3 Kinase p110 $\alpha$ (C73F8) Rabbit mAb (Cat. 4249), AKT Antibody (Cat. 9272), Phospho-AKT (Ser473) (D9E) XP Rabbit mAb (Cat. 4060) and Anti-Rabbit IgG HRP-linked antibodies (Cat.7074) were purchased from Cell Signaling Technology (Danvers, USA). Anti-NOS3 antibody [EPR19296] (Cat. Ab199956) was purchased from Abcam (Shanghai, China).

Methanol (HPLC grade) was purchased from Sinopharm Chemical Reagent Co., Ltd. (Shanghai, China). Formic acid (HPLC grade) was purchased from Aladdin Reagent Co., Ltd. (Shanghai, China). The reference standard of shikimic acid (lot No. C11015240) was purchased from Shanghai Macklin Biochemical Co., Ltd. The reference standard of isoengelitin (lot No. ZW190519-14) was purchased from Stanford Analytical Chemicals Inc.
The reference standard of 4-dicaffeoylquinic acid (lot No. 34770010) was purchased from ANPEL Laboratory Technologies (Shanghai) Inc. The reference standard of p-hydroxybenzoic acid (lot No. H1926195) was purchased from Shanghai Aladdin Reagent Co., Ltd. The reference standards of engeletin (lot No. 111906-201102), astilbin (lot No. 111798-201504), ferulic acid (lot No. 11073-201313), luteolin (lot No. 111520-201605), isochlorogenic acid C (lot No. 111894-201102), salicylic acid (lot No. 100106-201104), and nicotinic acid (lot No. 100434-201603) were purchased from National Institutes for Food and Drug Control (Beijing, China). The reference standards of neoastilbin (lot No. DST191209077), isoastilbin (lot No. DST190922-216), neoisoastilbin (lot No. DST191025-078) were purchased from Chengdu Pufei De Biotech Co., Ltd.

\section{Animals and experimental design}

A total of 40 male Spontaneously hypertensive rats (SHR) (180-220 g), aged 10 weeks, were provided by Beijing Vital River Laboratory Animal Technologies Co. Ltd (Beijing, China, certificate number: SCXK-JING 2016-0006). All animals were maintained under standard laboratory conditions with a regular 12-h light/dark cycle, relative humidity of $50 \pm 5 \%$, and the temperature was maintained at $25 \pm 2{ }^{\circ} \mathrm{C}$. The experimental procedures were approved by the Institutional Animal Ethics Committee (IAEC), Guangxi Medical University.

The rats were provided with standard rat chow and water ad libitum. After an acclimatization period for two weeks, the basic value of blood pressure, body weight, and heart rate were measured. SHRs were randomly assigned to five groups based on the basic value of blood pressure: model group (saline, $10 \mathrm{~mL} / \mathrm{kg}$ ), captopril group $(0.03 \mathrm{~g} / \mathrm{kg})$, LFG high dose group $(20 \mathrm{~g} / \mathrm{kg})$, LFG middle dose group (10 g/ $\mathrm{kg})$, LFG low dose group ( $5 \mathrm{~g} / \mathrm{kg})$, eight rats per group. Saline served as a negative control and captopril, a proven hypertensive drug [23], as a positive control. LFG and captopril were administered twice a day intragastrically for 3 weeks. The systolic blood pressure, body weight, and heart rate of rats were measured every 3 days. The blood pressure and heart rate were measured using ALC-NIBP non-invasive blood pressure system (Shanghai Alcott Biotech Co., Ltd, China) at the tail artery employing the tail-cuff method, while body weight was measured using an electronic balance (CP214, Ohaus, USA). When the experimental period was complete, rats were anesthetized and blood was collected from the abdominal aorta. The serum samples were obtained after the blood samples were centrifuged. The heart and thoracic aorta were collected respectively for hematoxylin-eosin (H\&E) staining and stored at $-80^{\circ} \mathrm{C}$ for real-time PCR and western blot analysis. 
Determination of serum NO, ANG II, and ET-1 content The serum NO level in serum was measured by Nitric oxide (NO) assay kit obtained from Nanjing Jiancheng Bioengineering Institute. The serum ANG II and ET-1 contents were measured respectively using commercially available immunoassay ELISA kits for rats.

\section{Heart histopathological analysis}

Heart tissue samples were fixed in $4 \%$ paraformaldehyde, dehydrated, and washed. The samples were embedded in paraffin and sliced into $5 \mu \mathrm{m}$ by a paraffin slicing machine. The sections were dewaxed in xylene and dehydrated in descending grades of ethanol. The sections were stained by hematoxylin for $5 \mathrm{~min}$. After washing, the sections were treated with eosin solution for 2 min for coloration, followed by ethanol dehydration and neutral gum sealing. Finally, the specimens were further observed and photographed under a BX53 microscope (Olympus, Takachiho, Japan).

\section{Network pharmacology analysis Composite compounds of LFG}

LFG consists of three herbs, namely Centella asiatica (L.) Urb., Eclipta prostrata (L.) L., Smilax glabra Roxb. The compounds of LFG were collected using the TCM Systems Pharmacology Database [24] (TCMSP, http:// tcmspw.com/tcmsp.php) (accessed 18th January 2018), TCM Integrated Database [25] (TCMID, http://www. megabionet.org/tcmid/) (accessed 18th January 2018), and Bioinformatics Analysis Tool for Molecular mechanism of TCM [26] (BATMAN-TCM, http://bionet.ncpsb. org/batman-tcm/) (accessed 19th January 2018). Candidate compounds were screened according to the criteria of oral bioavailability $(\mathrm{OB})>30 \%$ of the pharmacokinetic parameters [27].

\section{Targets collection}

The SMILES of the candidate compounds in LFG were used as the inputs of target fishing database, obtained from Pubchem database (https://pubchem.ncbi.nlm.nih. gov/). Subsequently, the predicted targets were retrieved from ChemMapper database [28] (http://lilab.ecust. edu.cn/chemmapper/) (accessed 26th January 2018), an online tool based on 3D similarity for targets prediction. The targets associated with hypertension were collected by Text-mined Hypertension, Obesity and Diabetes candidate gene database [29] (T-HOD, http://bws.iis.sinica. edu.tw/THOD/) (accessed 28th January 2018), a tool developed to help trace existing research on three kinds of cardiovascular disease. Furthermore, the overlapped targets both related to the candidate compounds and hypertension were kept for network construction and analysis.

\section{Network construction}

Network construction was performed as follows: (1) Herb-compound network; (2) Compound-target network; (3) Hypertension-target network; (4) The proteinprotein interaction (PPI) network of intersection targets between compounds and hypertension targets.

All the networks were created via Cytoscape (htttps:// cytoscape.org/, Version 3.2.1), a general platform for complex network analysis and visualization [30]. The PPI network was constructed by Search Tool for the Retrieval of Interacting Genes/Proteins database [31] (STRING, https://string-db.org/, Version 11.0) with medium confidence 0.400 by default, and then visualized in Cytoscape. The topological parameters of nodes in PPI network were calculated by Network Analyzer, and the nodes whose degree values were twice the average degree values of the network were selected as the hub targets for further analysis.

\section{Pathway enrichment}

The Database for Annotation, Visualization and Integrated Discovery [32] (DAVID, https://david.ncifcrf.gov/, Version 6.8) was applied for Kyoto Encyclopedia of Genes and Genomes (KEGG) pathway enrichment analysis of the hub targets. $P$-values were set at 0.05 as the cut-off criterion.

\section{Real-time RT-PCR analysis}

Quantitative PCR analysis was performed to examine the mRNA expression levels of predicted hub targets. In brief, total RNA was extracted from thoracic aorta tissue using Trizol reagent, and the quality and purity of RNA were evaluated by Nanodrop2000 (Thermo Fisher, USA). The RNA $(2 \mu \mathrm{g})$ was reverse-transcribed using the HighCapacity cDNA Reverse Transcription Kit under reaction conditions with $25{ }^{\circ} \mathrm{C}$ for $10 \mathrm{~min}, 37^{\circ} \mathrm{C}$ for $120 \mathrm{~min}$ and $85{ }^{\circ} \mathrm{C}$ for $5 \mathrm{~min}$. Real-time PCR amplification was performed with SYBR Green Master Mix on the 7300 Realtime PCR system (Applied Biosystems) following the manufacturer's instructions. The relative RNA expression levels were calculated using the $\Delta \Delta$ cycle threshold method [33], and $\beta$-actin was applied to normalize the expression levels of target genes for each sample. Primer sequences were listed in Table 1.

\section{Western blot analysis}

The protein expression levels of endothelial nitric oxide synthase 3 (NOS3), proto-oncogene tyrosine-protein kinase SRC (SRC), phosphatidylinositol 3 kinase (PI3K), protein kinase $\mathrm{B}$ (AKT) and $\mathrm{p}$-AKT were determined by western blot analysis. Total proteins extracted from thoracic aorta by lysis buffer supplemented with phosphatase and protease inhibitors. The protein concentrations were 
Table 1 Primer sequence used for PCR analysis

\begin{tabular}{|c|c|c|}
\hline Gene & Forward & Reverse \\
\hline NOS3 & 5'-CAGAGATTGGCATGAGGGACC-3' & 5'-TCCACAGTGATGAGGTTGTCC-3' \\
\hline SRC & 5'-CAAGATCACTAGACGGGAATCAG-3' & 5'-GTTTCACATTTAGGCCCTTGG-3' \\
\hline PTGS2 & 5'-ATCAGAACCGCATTGCCTCT-3' & 5'-GCCAGCAATCTGTCTGGTGA-3' \\
\hline NGF & 5'-GTCTGGGCCCAATAAAGGCT-3' & 5'-TGTACGCCGATCAAAAACGC-3' \\
\hline VEGFA & 5'-CGTCCTGTGTGCCCCTAATG-3' & 5'-TGTGCTGGCTTTGGTGAGGT-3' \\
\hline EGF & 5'-CTACTACAGGACTCGGAAGCAG-3' & 5'-GTTGGGGACCAGAAGACACC-3' \\
\hline EGFR & 5'-AGCCGTCCTGTCCAACTATG-3' & 5'-TTGCTAAATCGCACAGCACC-3' \\
\hline ERK2 & 5'-ATTGGTCAGGACAAGGGCTCA-3' & 5'-CCACTACGACCAGAACTGCC-3' \\
\hline $\mathrm{CCL} 2$ & 5'-TGCAGGTCTCTGTCACGCTTC-3' & 5'-TTCTCCAGCCGACTCATTGG-3' \\
\hline NPY & 5'-GCCAGATACTACTCCGCTCTG-3' & 5'-GTCTCAGGGCTGGATCTCTTG-3' \\
\hline ESR1 & 5'-CAGACAGGGAGCTGGTTCATA-3' & 5'-GCACACTCCAGAAGGTGAACT-3' \\
\hline $\mathrm{TH}$ & 5'-GTCTCAGAGCAGGATGCCAAG-3' & 5'-ATCCTCGATGAGACTCTGTCGC-3' \\
\hline$\beta$-actin & 5'-GTCAGGTCATCACTATCGGCAAT-3' & 5'-AGAGGTCTTTACGGATGTCAACGT-3' \\
\hline
\end{tabular}

measured by BCA Protein Assay Kit. Protein samples $(30 \mu \mathrm{g})$ were separated on $10 \%$ sodium dodecyl sulphatepolyacrylamide gel electrophoresis (SDS-PAGE) and then transferred to polyvinylidene difluoride (PVDF) membranes. The membranes were blocked for $1 \mathrm{~h}$ at $4{ }^{\circ} \mathrm{C}$ with $5 \%$ nonfat milk, while the phosphorylated proteins were blocked with $5 \%$ bovine serum albumin (BSA), and incubated overnight with anti-NOS3 (1:1000), antiSRC (1:1000), anti-PI3K (1:1000) antibody, anti-AKT (1:1000) antibody, anti-p-AKT (1:1000) antibody and anti-GAPDH (1:5000) antibody, respectively. The membranes were washed 3 times and incubated with secondary antibody (horseradish peroxidase-conjugated, 1:5000 dilution) for $1 \mathrm{~h}$ at room temperature. The GAPDH was applied to show equal protein loading for each sample. The bands were visualized by chemiluminescence using MiniChemi 610 Plus (Sage Creation, Beijing), and Image J software (Version 1.43) was used to analyze the intensity of bands.

\section{Molecular docking}

Molecular docking is a computational tool that can predict the interaction energy between receptors and ligands. The binding mode and affinity between targets and compounds were performed using the Surflex-Dock (SFXC) module of Sybyl X2.0 and visualized with PyMOL (Version 1.5.0.3). The structures of the potential active compounds related to the potential targets were downloaded from the Pubchem database and converted into mol2 format by Open Babel GUI (Version 2.2.1). All the crystal structures of the targets were downloaded from Protein Data Bank (PDB, https://www.rcsb.org/), including endothelial nitric oxide synthase (NOS3) (PDB ID: 4D1O), SRC (PDB ID: 1A07), PI3K (PDB ID: 4L23), and AKT (PDB ID: $1 \mathrm{H} 1 \mathrm{O}$ ). Before docking, the proteins were subjected to the necessary preparation steps (remove water molecules and add hydrogen atoms), and ligands were optimized by the Tripos force field. The total score (pKd) calculated by SFXC was used to determine the affinity of receptors and ligands. The total score greater than 6 was regarded as good protein-ligand binding.

\section{UPLC-QTOF/MS analysis of LFG}

LFG extract was dissolved by ultrasonification in $50 \%$ methanol (in water) for $1 \mathrm{~h}$, and filtered through a $0.22 \mu \mathrm{m}$ syringe filter before analysis.

UPLC analysis conditions were as follows: Separation of the compounds was carried out on a Dionex Ultimate 3000 UPLC system (Thermo Fisher, USA) equipped with a SunFire C18 column $(250 \mathrm{~mm} \times 4.6 \mathrm{~mm}$, i.d., $4.6 \mu \mathrm{m}$, Waters, USA). The analytical column was maintained at a temperature of $35{ }^{\circ} \mathrm{C}$ and the mobile phase was composed of water A (containing $0.1 \%$ formic acid) and acetonitrile B. A solvent gradient system was used: $10-10 \%$ B for $0-10 \mathrm{~min}, 10-30 \%$ B for $10-50 \mathrm{~min}, 30-90 \% \mathrm{~B}$ for $50-58 \mathrm{~min}, 90-90 \%$ B for $58-64 \mathrm{~min}, 90-10 \%$ B for 64-65 $\mathrm{min}$ and $10-10 \% \mathrm{~B}$ for $65-75 \mathrm{~min}$. The flow rate was $0.8 \mathrm{~mL} / \mathrm{min}$. The injection volume was $10 \mu \mathrm{L}$. A DAD detector and a mass spectrometer detector were connected in series behind the column. The outlet of the DAD detector was split into the mass spectrometer detector with a split ratio of 4:1.

MS analysis conditions were as follows: MS analysis was performed on the Bruker definition accurate mass quadrupole time-of-flight (Q-TOF) Impact II mass spectrometer (Bruker Daltonics Inc., GER) equipped with electrospray ionization (ESI) source. The capillary voltage was set at $2500 \mathrm{~V}$, the dry temperature was $200{ }^{\circ} \mathrm{C}$, the dry gas rate was set at $4.0 \mathrm{~L} / \mathrm{min}$, the energies for collision induced dissociation (CID) were $10 \mathrm{eV}$ for the precursor 
ion and 32.5-97.5 eV for fragmentation information. A full-scan mass range of m/z 50-2000 was scanned. Data were acquired in Line Spectra mode.

The contents of shikimic acid, nicotinic acid, p-hydroxybenzoic acid and salicylic acid in LGF were determined by LC-MS/MS. Four reference substances were mixed with methanol, and a series of curve solutions were prepared. Agilent1290-6490 liquid chromatography-mass spectrometry was used for the determination with acetonitrile- $0.1 \%$ formic acid solution as mobile phase. Shikimic acid and nicotinic acid were determined by Waters SunFire C18 column $(250 \times 4.6 \mathrm{~mm}$, $5 \mu \mathrm{m})$. p-hydroxybenzoic acid and salicylic acid were determined by Agilent Eclipse Plus C18, RRHD column $(2.1 \times 100 \mathrm{~mm}, 1.8 \mu \mathrm{m})$.

\section{In vitro experiment verification Cell viability assessment}

Human umbilical vein endothelial cells (HUVEC) were cultured in endothelial cell growth medium-2 (EGM-2) (LONZA, Walkersville, MD USA, Cat. CC-4176) containing $2 \%$ FBS, $0.2 \mathrm{~mL}$ hydrocortisone, $2 \mathrm{~mL}$ hFGF-B, $0.5 \mathrm{~mL}$ VEGF, $0.5 \mathrm{~mL}$ R3-IGF-1, $0.5 \mathrm{~mL}$ ascorbic acid, 0.5 $\mathrm{mL}$ hEGF, $0.5 \mathrm{~mL}$ GA-1000 and $0.5 \mathrm{~mL}$ heparin. HUVEC $\left(2 \times 10^{4}\right.$ cells/well $)$ were seeded and allowed to adhere in 96-well plates overnight. The cells were pre-treated for $24 \mathrm{~h}$ with p-hydroxybenzoic acid $(0.1 \mu \mathrm{M}, 1 \mu \mathrm{M}, 10 \mu \mathrm{M}$, $100 \mu \mathrm{M})$, shikimic acid $(0.1 \mu \mathrm{M}, 1 \mu \mathrm{M}, 10 \mu \mathrm{M}, 100 \mu \mathrm{M})$, salicylic acid $(1 \mu \mathrm{M}, 10 \mu \mathrm{M}, 100 \mu \mathrm{M}, 1000 \mu \mathrm{M})$, and nicotinic acid $(1 \mu \mathrm{M}, 10 \mu \mathrm{M}, 100 \mu \mathrm{M}, 1000 \mu \mathrm{M})$, then $\mathrm{H}_{2} \mathrm{O}_{2}$ with a final concentration of $600 \mu \mathrm{M}$ was added to stimulate the cells for $6 \mathrm{~h}$. Captopril was used as a positive control. After incubation, the supernatants were removed, washed with PBS, and replaced with fresh medium. The cells were added with $10 \mu \mathrm{L}$ CCK8 for $2 \mathrm{~h}$ in dark, and the absorbance was measured at $450 \mathrm{~nm}$ in a microplate reader (Multiskan FC, Thermo Fisher, USA).

\section{NO release assay}

After HUVEC were treated, the supernatant was collected and the level of $\mathrm{NO}$ was determined using assay kit according to the protocol described by the manufacturer.

\section{Statistical analysis}

Statistical analysis was performed by SPSS software (Version 22.0). The data were expressed as mean \pm SEM. The parameters among different groups were compared by one-way analysis of variance (ANOVA) followed by LSD (equal variances) or Dunnett's T3 (unequal variances). $P$-value $<0.05$ was considered as statistically significant.

\section{Results}

\section{LFG exerts an anti-hypertensive effect in SHR}

To assess the anti-hypertensive effect of LFG, SHRs were treated with different doses of LFG for 3 weeks. As shown in Fig. 2A, the blood pressure of LFG treatment groups was significantly decreased compared to model group $(P<0.05)$. But neither body weight nor heart rate has differences between LFG treatment groups and the model group $(P>0.05)$ (Fig. 2B, C).

\section{Effect of LFG on serum NO, ANG II and ET-1 levels}

Serum NO, ANG II and ET-1 levels of animals from various groups were summarized in Fig. 3. The level of serum NO increased significantly in LFG high-dose group and LFG middle-dose group compared to the model group $(P<0.01$ or 0.05$)$ (Fig. 3A). However, there was no effect on the contents of ANG II and ET-1 in serum after treatment with different doses of LFG $(P>0.05)$ (Fig. 3B, C).

\section{Effect of LFG on myocardial morphological change}

As shown in Fig. 4, myocardial samples of the model group developed obvious cardiac hypertrophy and fibrosis, because the cardiomyocytes were swollen and sparse, the area of single cardiomyocyte increased, and
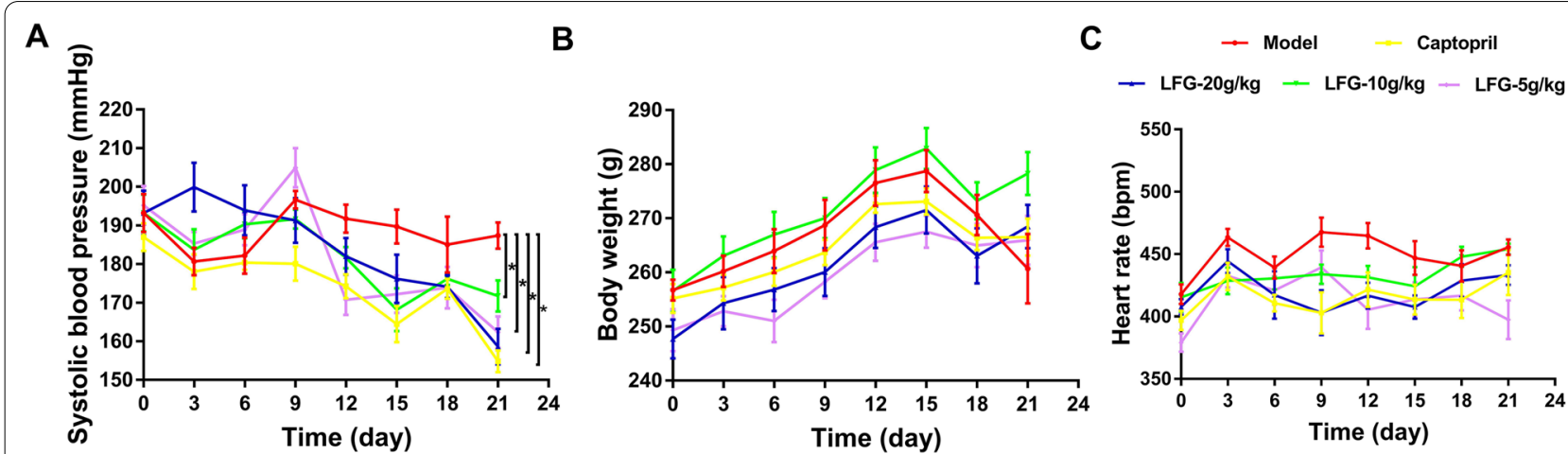

Fig. 2 Effect of LFG on blood pressure, body weight and heart rate of SHR. A Blood pressure changes; B body weight changes; $\mathbf{C}$ heart rate changes. Compared with the model group, ${ }^{*} P<0.05$ 

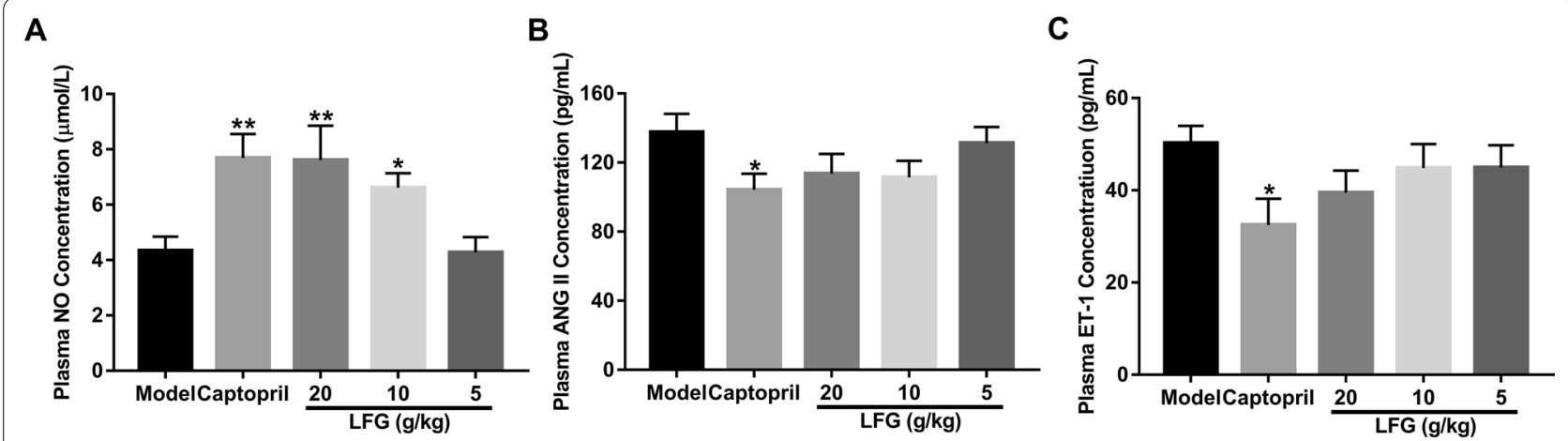

Fig. 3 Effect of LFG on A NO, B Ang II and C ET-1 levels in serum of SHR. Compared with model group, * $P<0.05$, ** $P<0.01$

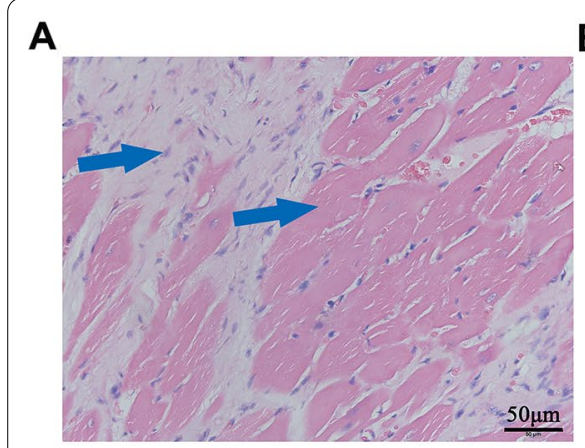

D
B

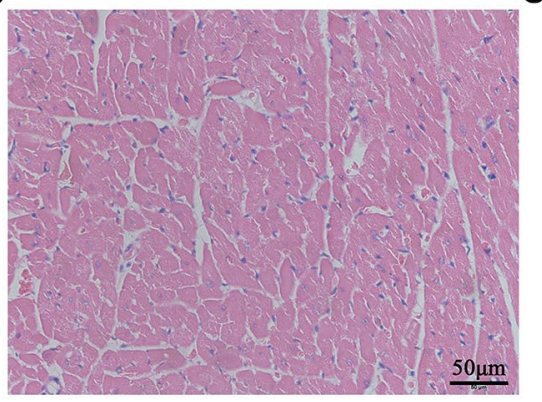

C

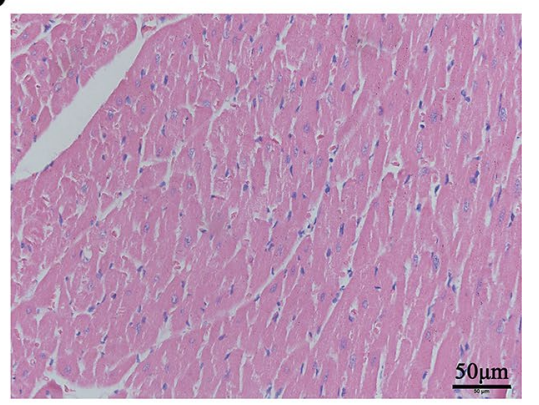

E

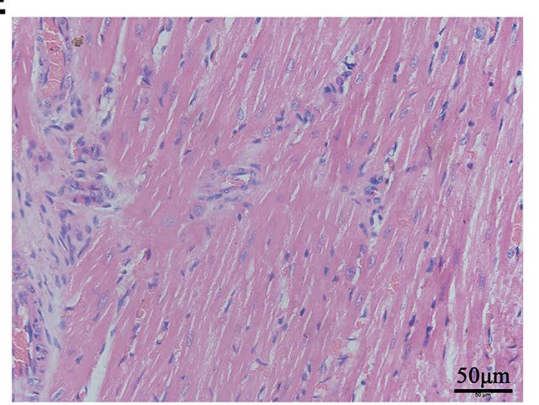

Fig. 4 H\&E staining results of heart tissue. A Model group; B Captopril group; C High-dose group; D Middle-dose group; E Low-dose group. Magnification $\times 400$, scale bar $=50 \mu \mathrm{m}$. The blue arrows indicate cardiac hypertrophy and fibrosis

the granular content and karyopyknosis in some myocardial cells increased (Fig. 4A). These phenomena were improved in captopril group (Fig. 4B). Compared with the model group, the swelling degree of myocardial cells and area of the single myocardial cell decreased in LFG treatment groups, and three doses of LFG administration reduced the area of myocardial fibrosis to a certain extent (Fig. 4C-E).

\section{Composite compounds of LFG}

A total of 70 compounds were collected according to the ADME threshold of $\mathrm{OB} \geq 30 \%$, and the herb-compound network was shown in Fig. 5A, which included 73 nodes and 77 edges. The ellipse nodes represented herbs, and the hexagon nodes were compounds. Among these compounds, the yellow parts were common components of Centella asiatica (L.) Urb. and Smilax glabra Roxb., and quercetin (red hexagon) was common compounds of 3 herbs.

\section{Compound-target network}

We predicted the putative targets of compounds based on the similarities of drug structures through the ChemMapper database. Since no relevant targets for the 17 

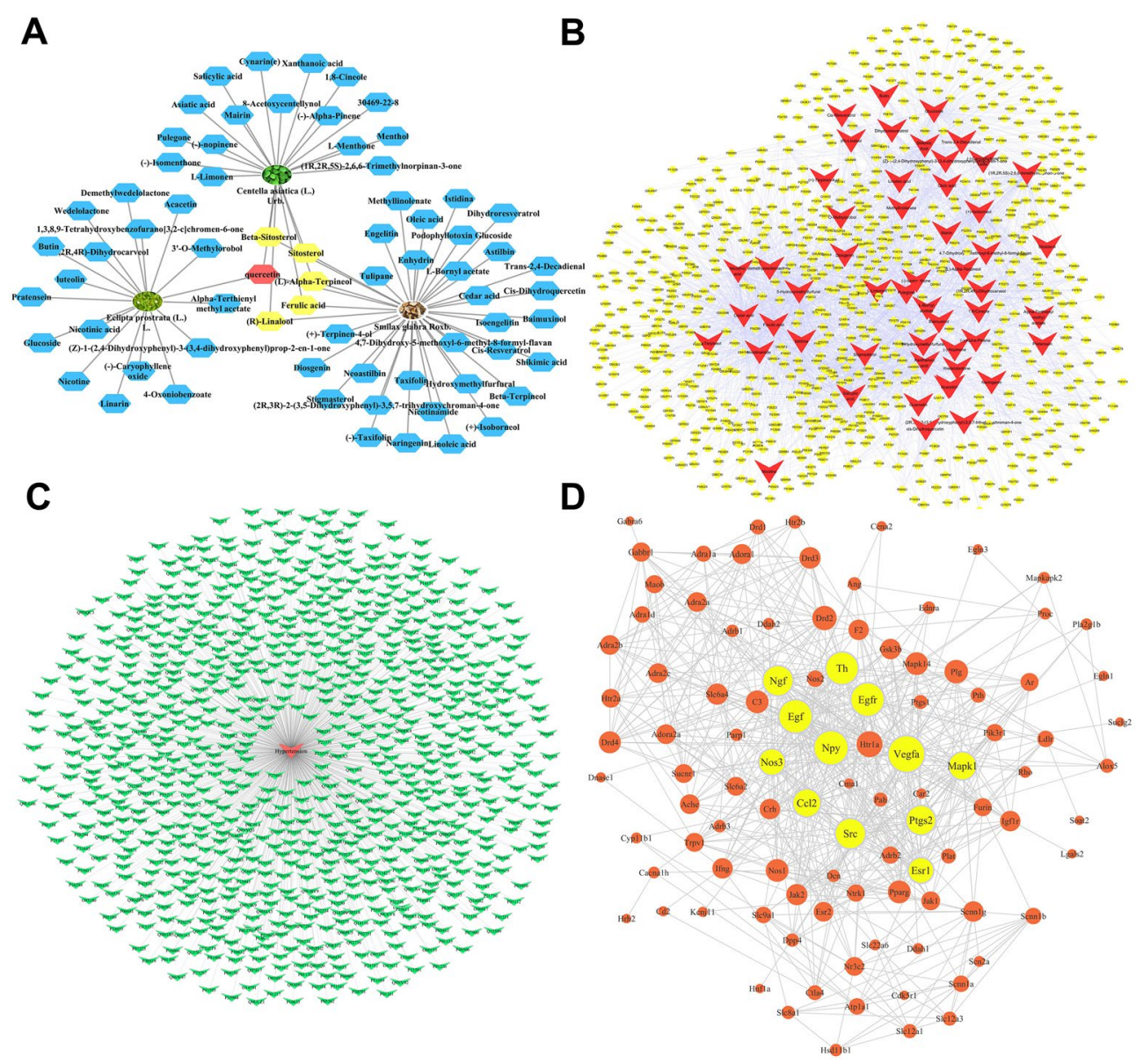

Fig. 5 The results of network pharmacology prediction. A The herb-compound network. The ellipse nodes represent herbs, and the hexagon nodes are compounds. Among these compounds, yellow parts are the common components of Centella asiatica (L.) Urb. and Smilax glabra Roxb., and quercetin (red hexagon) is common compounds of 3 herbs. B The compound-target network. The $V$ shape nodes represent 53 compounds, and the 765 yellow nodes are targets corresponding to the compounds. C The hypertension-target network. In this figure, the red node in the center is hypertension, and the green nodes represent gene targets. D The protein-protein interaction network within the common targets. It shows the relationship between 101 common targets. The size of nodes changes from big to small according to degree values, and the 12 yellow nodes are key targets after screening

herbal compounds were observed, they were removed from 70 herbal compounds. A total of 765 targets were predicted to be hit by the chemical constituents containing in LFG, and the detailed information about the targets was shown in our previous study [22]. The compoundtarget network was shown in Fig. 5B, the $\mathrm{V}$-shaped nodes represented 53 compounds, and 765 yellow nodes were targets corresponding to the components.

\section{Hypertension targets and key targets}

After collection, 828 hypertension related genes were obtained from T-HOD database (Additional file 1: Table S2). The hypertension-target network was established, as shown in Fig. 5C (the red node in the center was hypertension, and the green nodes represented gene targets). A total of 101 overlapped genes related to candidate compounds and hypertension were kept for PPI network construction using STRING database. The PPI network was visualized by Cytoscape software, as shown in Fig. 5D, in which the size of nodes changes from big to small according to degree values, and the 12 yellow nodes were recognized as the key targets after screening, including NOS3, SRC, prostaglandin $\mathrm{G} / \mathrm{H}$ synthase 2 (PTGS2), nerve growth factor (NGF), vascular endothelial growth factor A (VEGFA), epidermal growth factor (EGF), epidermal growth factor receptor (EGFR), mitogen-activated protein kinase 1 (ERK2), C-C motif chemokine 2 (CCL2), neuropeptide Y (NPY), estrogen receptor (ESR1), and tyrosine 
3-monooxygenase $(\mathrm{TH})$. There were 37 compounds associated with 12 key genes (Table 2).

\section{Pathway enrichment of key targets}

To clarify the crucial pathways among the key targets in hypertension treatment, KEGG pathway enrichment analysis was performed. The top 10 pathways were shown in Fig. 6A, including Bladder cancer, VEGF signaling pathway, Rap1 signaling pathway, Estrogen signaling pathway, HIF-1 signaling pathway, Oxytocin signaling pathway, PI3K-AKT signaling pathway, Pancreatic cancer, Proteoglycans in cancer, and Prolactin signaling pathway.
The compound-target-pathway network was summarized in Fig. 6B, where compounds were indicated by purple nodes; gene targets were shown as yellow nodes; 34 pathways were labeled with green nodes.

\section{RT-qPCR and western blot verification}

To further validate the 12 hub targets predicted from network pharmacology approach, the mRNA expression levels were measured by RT-qPCR. As shown in Fig. 7 , the results revealed that the mRNA expression levels of NOS3 and SRC in LFG high-dose group were significantly increased compared with the model group

Table 2 The information of 12 key targets between compounds and hypertension targets

\begin{tabular}{|c|c|c|c|}
\hline Gene & Compounds & Gene & Compounds \\
\hline VEGFA & Glucoside & MAPK1 & Cedar acid \\
\hline NPY & Ferulic Acid & MAPK1 & Ferulic Acid \\
\hline EGF & Salicylic acid & NOS3 & L-Bornyl acetate \\
\hline EGF & Nicotinic acid & NOS3 & p-Hydroxybenzoic acid \\
\hline EGF & p-Hydroxybenzoic acid & NOS3 & Salicylic acid \\
\hline EGFR & Naringenin & NOS3 & Pulegone \\
\hline $\mathrm{TH}$ & $(1 R, 2 R, 5 S)-2,6,6$-trimethylnorpinan-3-one & NOS3 & Cedar acid \\
\hline $\mathrm{TH}$ & Ferulic Acid & NOS3 & Nicotinic acid \\
\hline $\mathrm{TH}$ & Histidine & NOS3 & Histidine \\
\hline NGF & (-)-alpha-Pinene & NOS3 & (R)-linalool \\
\hline NGF & p-Hydroxybenzoic acid & NOS3 & 5-Hydroxymethylfurfural \\
\hline NGF & (-)-nopinene & ESR1 & L-Bornyl acetate \\
\hline SRC & Shikimic Acid & ESR1 & $\begin{array}{l}(1 \mathrm{R}, 2 \mathrm{R}, 5 \mathrm{~S})-2,6,6 \text {-trimethylnorpinan- } \\
\text { 3-one }\end{array}$ \\
\hline SRC & Nicotinic acid & ESR1 & Pratensein \\
\hline SRC & Histidine & ESR1 & Alpha-Terthienyl methyl acetate \\
\hline PTGS2 & Naringenin & ESR1 & Diosgenin \\
\hline PTGS2 & Histidine & ESR1 & (+)-Isoborneol \\
\hline PTGS2 & Demethylwedelolactone & ESR1 & Sitosterol \\
\hline PTGS2 & Acacetin & ESR1 & Stigmasterol \\
\hline PTGS2 & Ferulic Acid & ESR1 & Butin \\
\hline PTGS2 & Xanthanoic acid & ESR1 & Baimuxinol \\
\hline PTGS2 & 5-Hydroxymethylfurfural & ESR1 & $\begin{array}{l}\text { (Z)-1-(2,4-dihydroxyphenyl)-3- } \\
\text { (3,4-dihydroxyphenyl)prop-2-en-1-one }\end{array}$ \\
\hline PTGS2 & (L)-alpha-Terpineol & ESR1 & (-)-nopinene \\
\hline PTGS2 & $(1 R, 2 R, 5 S)-2,6,6$-trimethylnorpinan-3-one & ESR1 & 1,8-cineole \\
\hline PTGS2 & Pulegone & ESR1 & (-)-alpha-Pinene \\
\hline PTGS2 & MENTHOL & ESR1 & Demethylwedelolactone \\
\hline PTGS2 & L-Limonen & ESR1 & 3'-O-Methylorobol \\
\hline PTGS2 & Salicylic acid & ESR1 & Wedelolactone \\
\hline PTGS2 & Nicotinic acid & ESR1 & Luteolin \\
\hline PTGS2 & p-Hydroxybenzoic acid & ESR1 & Acacetin \\
\hline PTGS2 & L-Bornyl acetate & ESR1 & Dihydroresveratrol \\
\hline PTGS2 & Cedar acid & ESR1 & Naringenin \\
\hline CCL2 & Ferulic Acid & ESR1 & Cis-resveratrol \\
\hline MAPK1 & p-Hydroxybenzoic acid & & \\
\hline
\end{tabular}




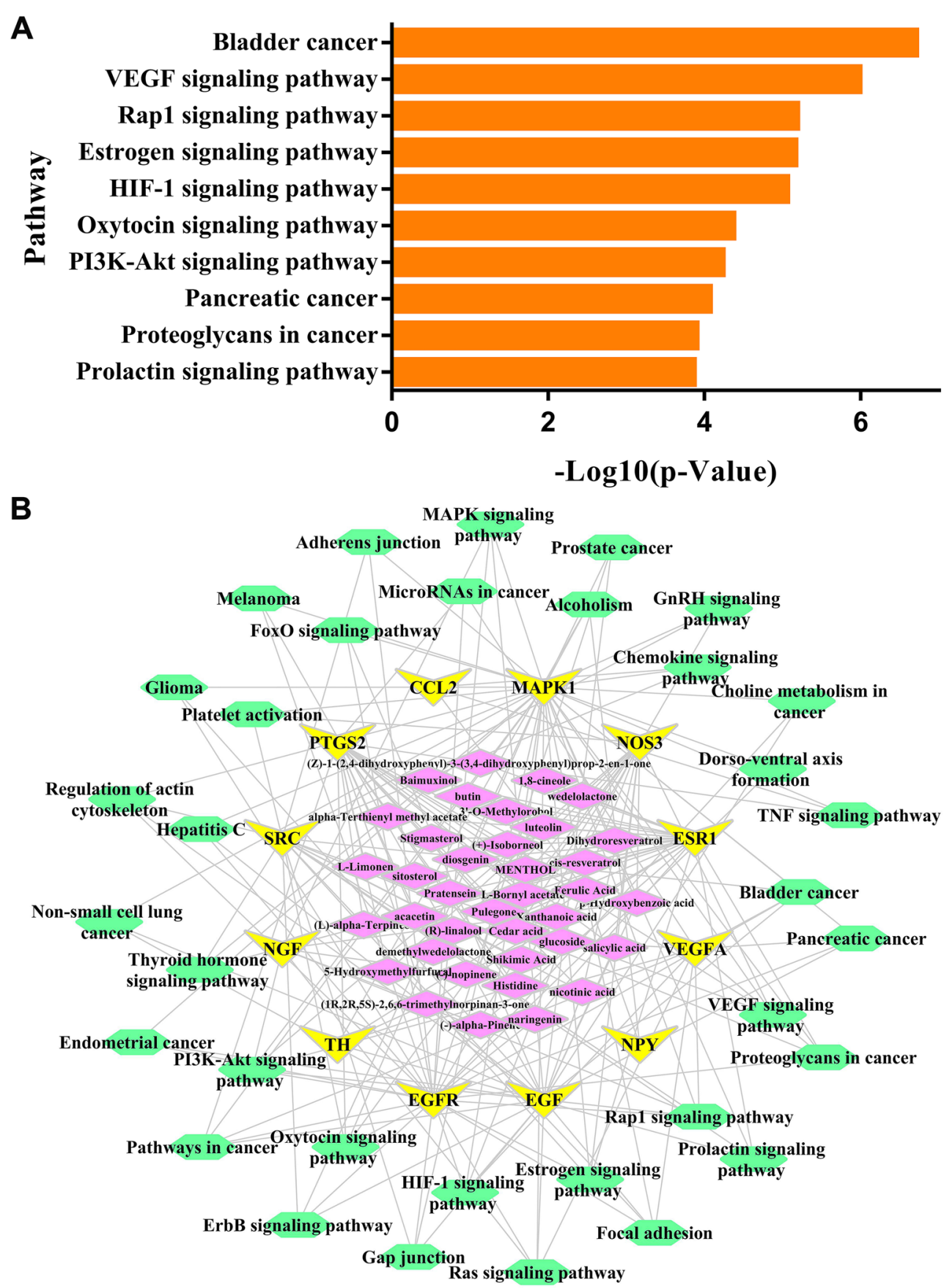

Fig. 6 A The relationship between TOP10 pathways and their - $\log 10$ (P). B The compound-target-pathway network. Compounds are indicated by 37 purple nodes; gene targets are shown as 12 yellow nodes; pathways are labeled with 34 green nodes

$(P<0.01$ or 0.05$)$. The mRNA expression level of NOS3 was significantly upregulated in LFG middle-dose group $(P<0.05)$ compared with the model group. For other predicted genes, there was no significant difference between the model group and the LFG treatment groups $(P>0.05)$ (Fig. 7C-L). Therefore, we only focused on NOS3 and
SRC in the following study. We further detected the protein levels of NOS3 and SRC in the thoracic aorta tissue. Western blot showed that the protein expression levels of NOS3 and SRC in LFG high- and middle-dose group were significantly increased compared with the model group $(P<0.01$ or 0.05$)$ (Fig. $8 \mathrm{~B})$. 


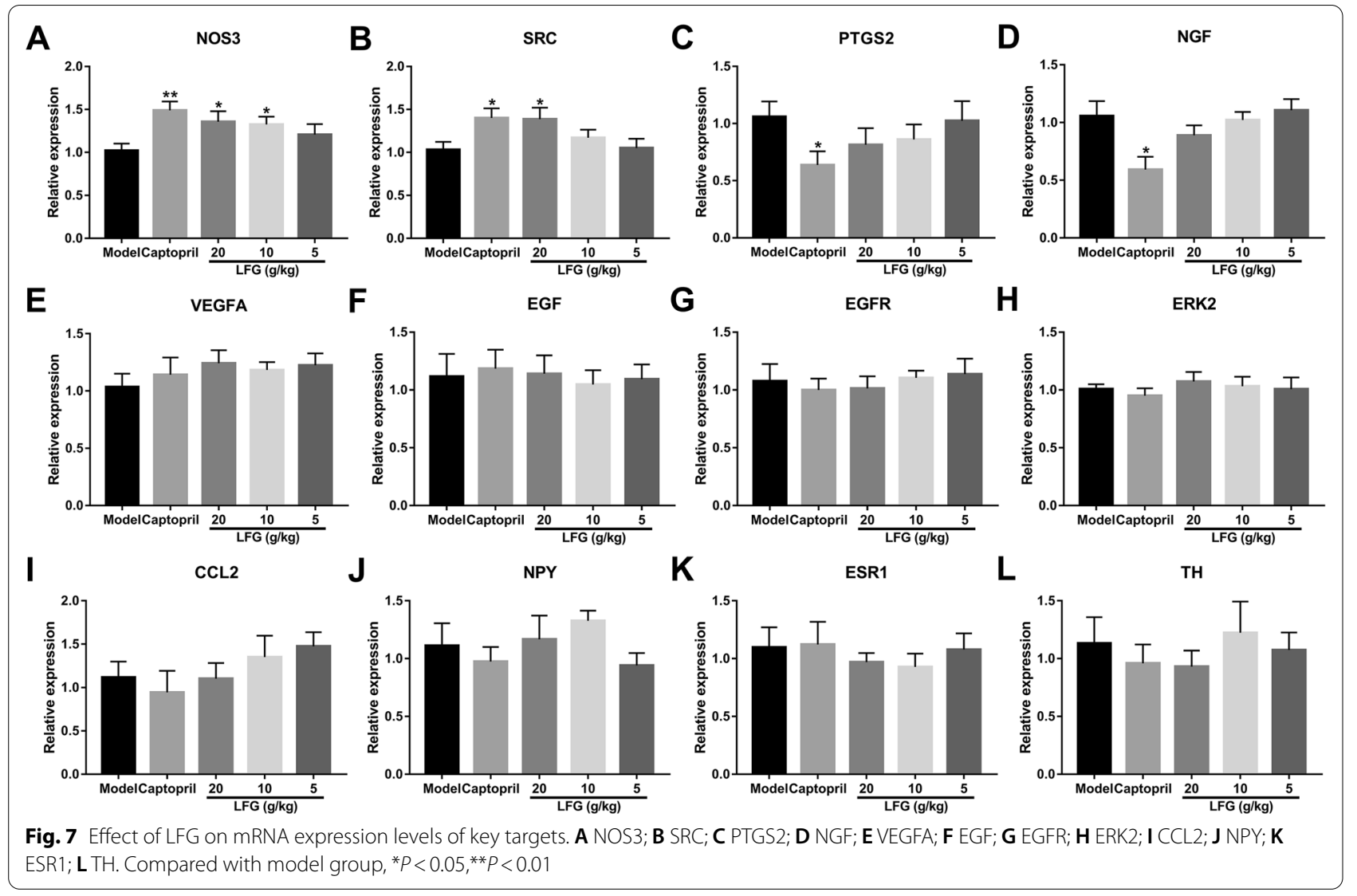

The results of RT-qPCR and western blot showed that LFG could regulate the mRNA and protein expressions of NOS3 and SRC associated with 10 compounds. At the same time, the pathway enrichment analysis of these 2 targets was performed, and the results showed that the antihypertensive effect of LFG might be exerted through the PI3K-AKT signaling pathway. Then we constructed the compound-target-pathway network of significant targets. As shown in Fig. 8A, these compounds were indicated by diamond nodes (p-Hydroxybenzoic acid, Nicotinic acid, Salicylic acid, (R)-Linalool, Cedar acid, L-Bornyl acetate, Pulegone, 5-Hydroxymethylfurfural, Shikimic acid, and Histidine), and the pathways were displayed as hexagon nodes.

To further verify the role of PI3K-AKT signaling pathway in the antihypertensive effect of LFG, the protein expression levels of PI3K, AKT, and p-AKT in the thoracic aorta tissue were measured by western blot analysis. As shown in Fig. 8C, expression levels of PI3K and p-AKT were increased in LFG high- and middle-dose group compared to the model group $(P<0.01$ or 0.05$)$. There was no significant difference in the level of total AKT expression between the model group and the treatment groups $(P>0.05)$.

\section{Molecular docking analysis}

To elucidate the interaction between targets (NOS3, SRC, PI3K, and AKT) and the 10 potential active compounds, a molecular docking simulation was performed using Sybyl X2.0 to investigate their binding modes. A docking score greater than 6 indicates good protein-ligand binding activity. The docking results of protein-ligand interaction were summarized in Additional file 1: Tables S3-S6. The binding modes of receptors and ligands with good affinity were shown in Fig. 9. In summary, histidine, cedar acid, linalool, and p-hydroxybenzoic acid were successfully docked in NOS3 (Fig. 9A-D). Shikimic acid, salicylic acid, histidine, cedar acid, nicotinic acid, and p-hydroxybenzoic acid were docked in SRC (Fig. 9E-J). Cedar acid, p-hydroxybenzoic acid, and linalool were docked in PI3K (Fig. 9K-M). Cedar acid, shikimic acid, and nicotinic acid were docked in AKT (Fig. 9N-P). Interestingly, cedar acid can be docked in NOS3, SRC, PI3K, and AKT, and p-hydroxybenzoic acid can be docked in NOS3, SRC, and PI3K. The molecular docking results revealed that 7 compounds (Cedar acid, p-hydroxybenzoic acid, histidine, shikimic acid, salicylic acid, linalool, nicotinic acid) exhibited good interaction with NOS3, SRC, PI3K, and AKT. 


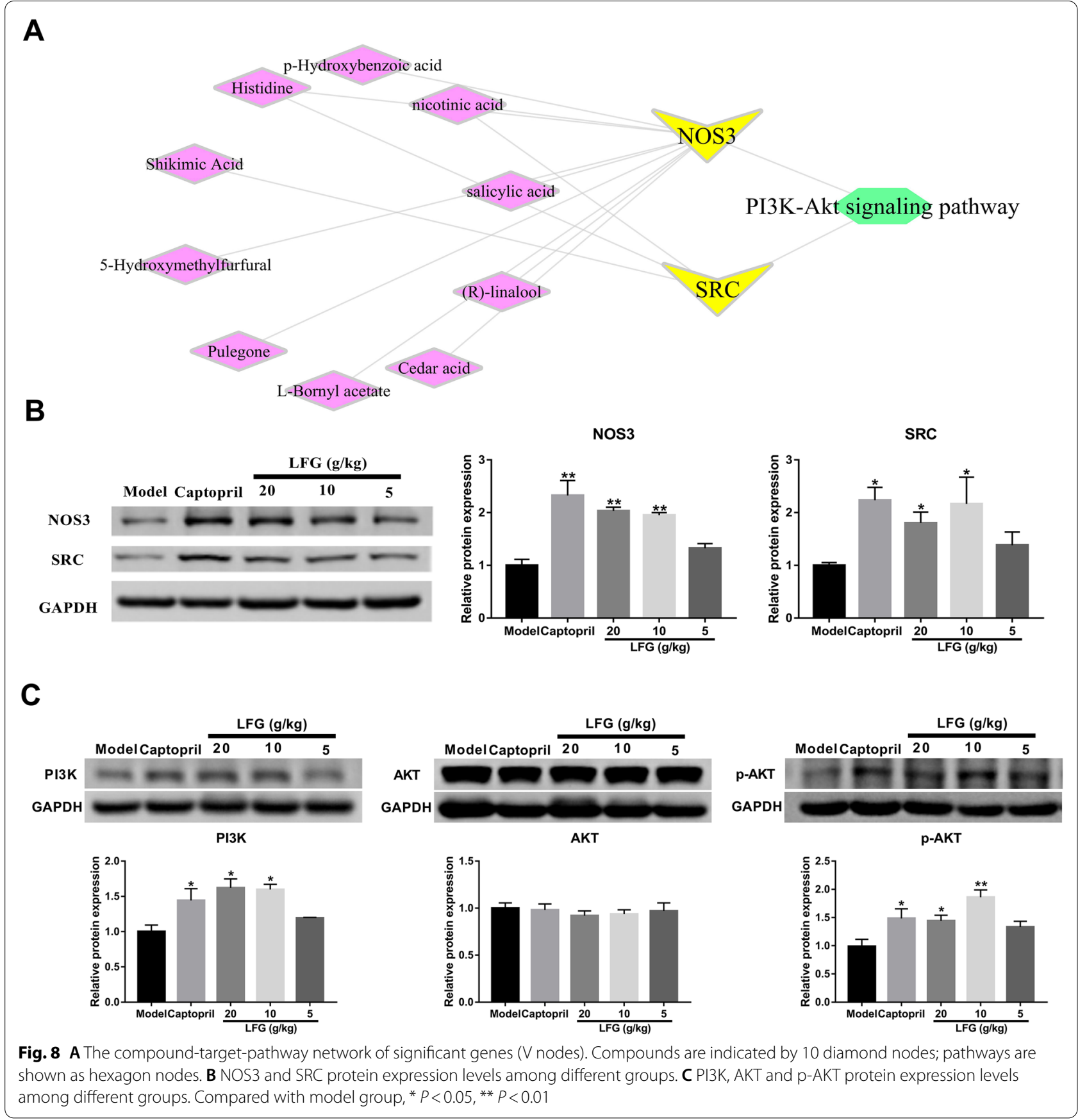

\section{LC-MS/MS analysis of LFG}

In order to verify whether the 7 components predicted by molecular docking exist in LFG, LC-MS/MS was p';/ erformed to analyze the chemical constituents of LFG. The representative base peak intensity (BPI) chromatogram in negative ion mode was shown in Fig. 10 L.A. After comparing each component in LFG with the reference standard (Additional file 2: Figure S1-S18), 18 compounds were detected, and the detail information of these compounds was shown in Table 3. Among these compounds, four compounds (p-hydroxybenzoic acid, shikimic acid, salicylic acid, nicotinic acid) were confirmed to exist in LFG and they docked well with NOS3, SRC, PI3K, and AKT. In addition, we determined the contents of above 4 compounds in LFG, and the results showed the contents of p-hydroxybenzoic acid, shikimic acid, salicylic acid and nicotinic acid in LFG were 100, 1360,36 and $36.8 \mu \mathrm{g} / \mathrm{g}$ respectively. 


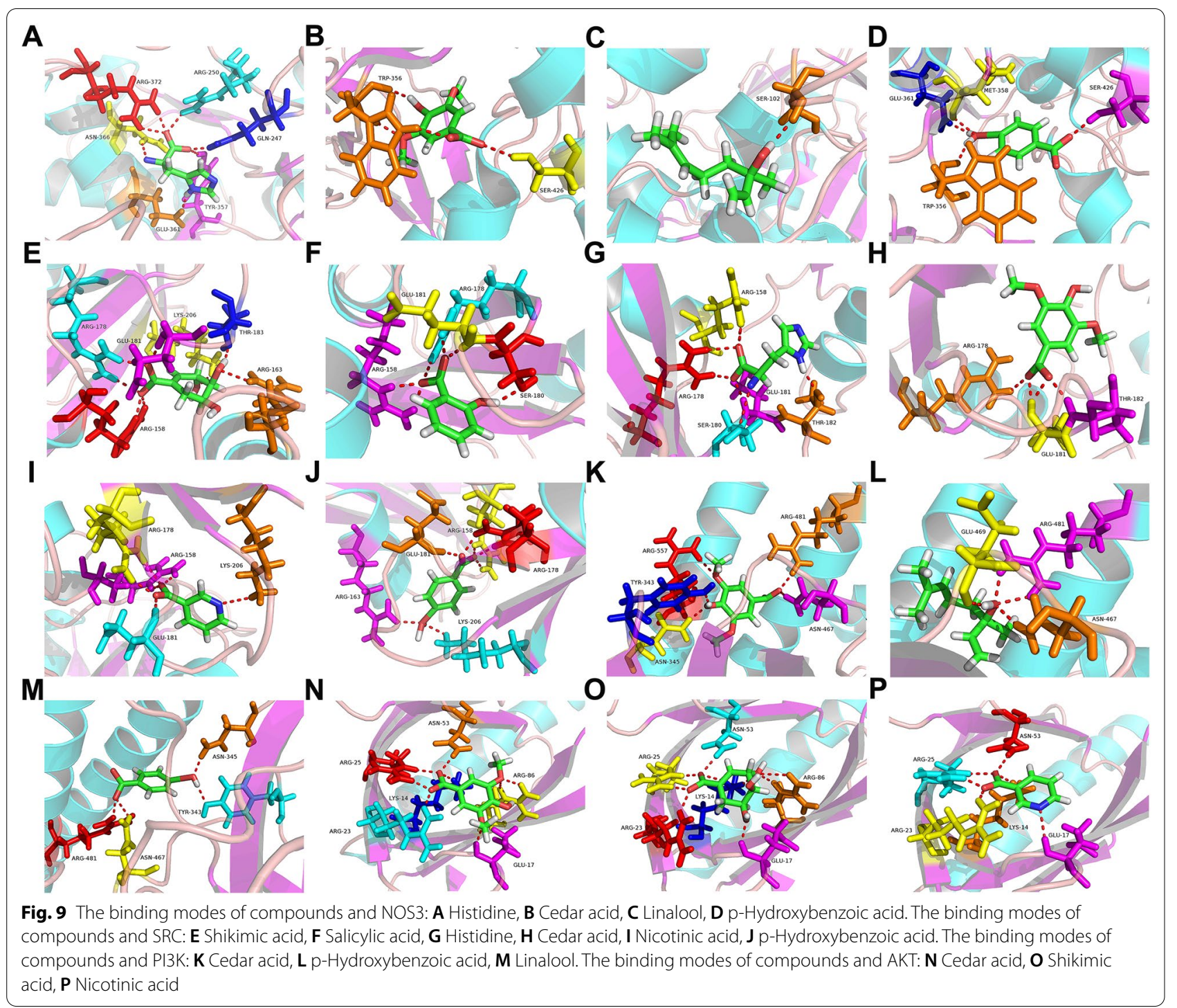

\section{Protective effect of compounds}

To further verify the antihypertensive effect of p-hydroxybenzoic acid, shikimic acid, salicylic acid and nicotinic acid in LFG. We detected the protective effect of 4 compounds on HUVEC in vitro. As shown in Fig. 10B, the cell viability in the $\mathrm{H}_{2} \mathrm{O}_{2}$-induced group was decreased significantly, whereas the cell viability in the groups treated with nicotinic acid $(10 \mu \mathrm{M}, 100 \mu \mathrm{M}$, $1000 \mu \mathrm{M})$ were increased $(P<0.05)$. Compared with $\mathrm{H}_{2} \mathrm{O}_{2}$-induced group, the NO level in cell supernatant of nicotinic acid $(10 \mu \mathrm{M}, 100 \mu \mathrm{M}, 1000 \mu \mathrm{M})$ groups were increased significantly (Fig. $10 \mathrm{C})(P<0.01$ or 0.05$)$. These results indicated that nicotinic acid exhibited protective effect on HUVEC and might be the potential active compound for LFG antihypertensive effect.

\section{Discussion}

Hypertension is a major risk factor for cardiovascular and cerebrovascular diseases as current complications, such as stroke, heart failure, myocardial infarction and renal failure [34]. Blood pressure can be controlled by changing diet and lifestyle, but drug treatment is used when these methods are ineffective. Drugs used to treat hypertension include calcium channel blockers, $\beta$-blockers, angiotensin converting enzyme inhibitors (ACEI) and angiotensin II receptor blockers. However, various side effects of these drugs have been reported [35, 36]. Longestablished Chinese herbal formulas can stabilize blood pressure, and improve the quality of life, minimize the risk factors associated with high blood pressure, and prevent organ damage to improve patient survival [37]. 


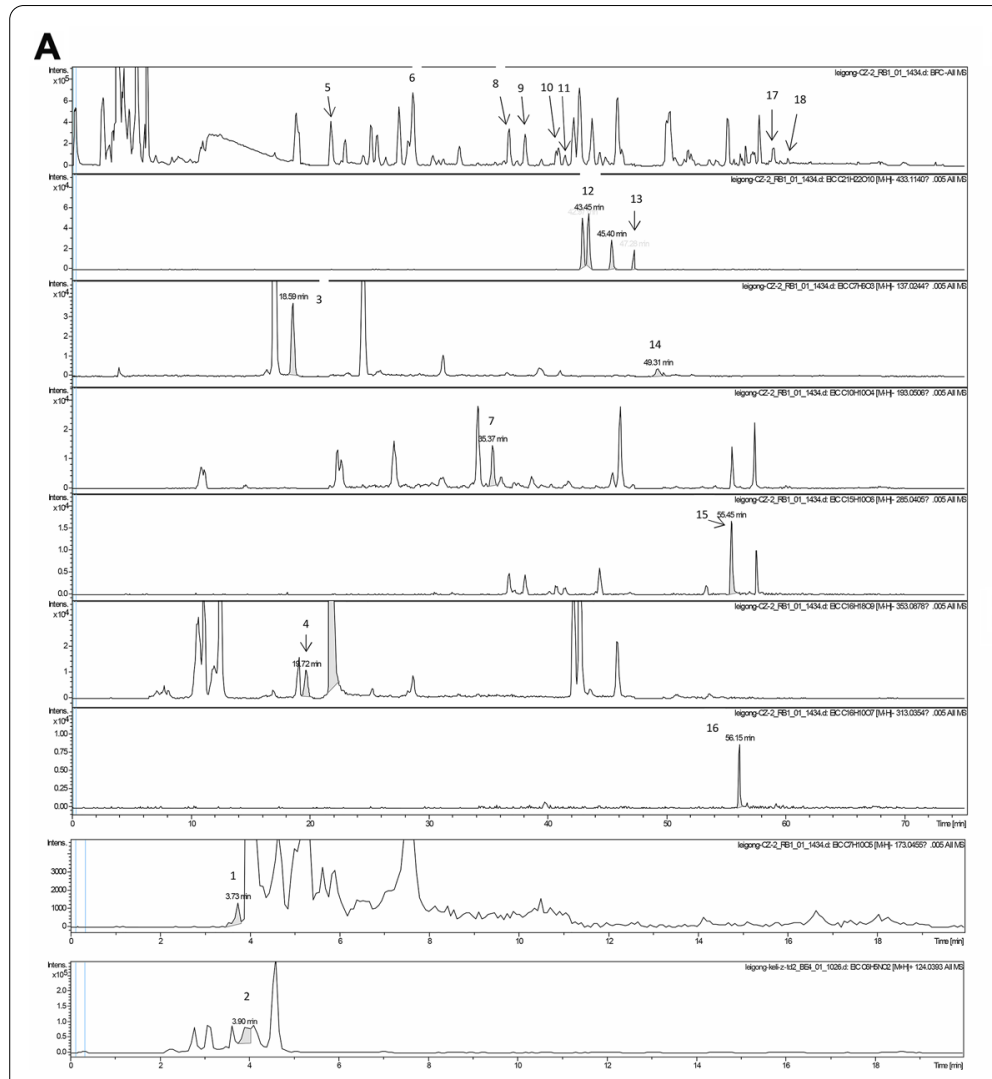

B

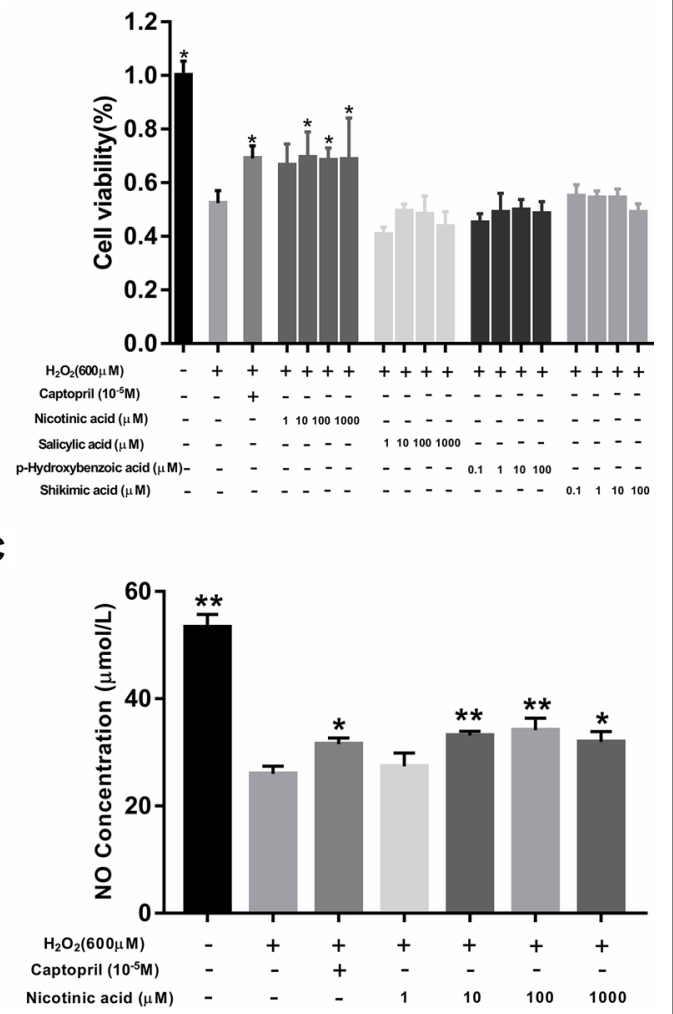

Fig. 10 A UPLC-QTOF/MS BPI chromatograms of LFG. B Protective effects of four compounds against $\mathrm{H}_{2} \mathrm{O}_{2}$ induced oxidative damage in HUVEC. C The effect of nicotinic acid on NO release in HUVEC. Compared with $\mathrm{H}_{2} \mathrm{O}_{2}$-induced group, ${ }^{*} P<0.05$, ${ }^{* *} P<0.01$

Table 3 Identify of the compounds of LFG by UPLC- Q-TOF/MS analysis in negative ion mode

\begin{tabular}{|c|c|c|c|c|c|c|c|}
\hline No. & R-T & $\mathrm{m} / \mathrm{z}$ & MS/MS & $\begin{array}{l}\text { Elemental } \\
\text { composition }\end{array}$ & lon form & ppm & Compounds \\
\hline 1 & 3.73 & 173.0458 & 93.0354 & $\mathrm{C}_{7} \mathrm{H}_{10} \mathrm{O}_{5}$ & {$[\mathrm{M}-\mathrm{H}]^{-}$} & -1.3 & Shikimic acid \\
\hline 2 & 3.90 & 124.0394 & $78.0334 / 80.0490$ & $\mathrm{C}_{6} \mathrm{H}_{5} \mathrm{NO}_{2}$ & {$[\mathrm{M}-\mathrm{H}]^{+}$} & -0.7 & Nicotinic acid \\
\hline 3 & 18.59 & 137.0244 & 93.0354 & $\mathrm{C}_{7} \mathrm{H}_{6} \mathrm{O}_{3}$ & {$[\mathrm{M}-\mathrm{H}]^{-}$} & 0.2 & p-Hydroxybenzoic acid \\
\hline 4 & 19.72 & 353.0882 & 191.0565 & $\mathrm{C}_{16} \mathrm{H}_{18} \mathrm{O}_{9}$ & {$[\mathrm{M}-\mathrm{H}]^{-}$} & -1.0 & Chlorogenic acid \\
\hline 5 & 21.78 & 353.0881 & $191.0563 / 173.0456$ & $\mathrm{C}_{16} \mathrm{H}_{18} \mathrm{O}_{9}$ & {$[\mathrm{M}-\mathrm{H}]^{-}$} & -0.9 & 4-Dicaffeoylquinic acid \\
\hline 6 & 28.69 & 515.1196 & $191.0563 / 179.0351$ & $\mathrm{C}_{25} \mathrm{H}_{24} \mathrm{O}_{12}$ & {$[\mathrm{M}-\mathrm{H}]^{-}$} & -0.1 & Isochlorogenic acid C \\
\hline 7 & 35.37 & 193.0509 & $106.0438 / 134.0376$ & $\mathrm{C}_{10} \mathrm{H}_{10} \mathrm{O}_{4}$ & {$[\mathrm{M}-\mathrm{H}]^{-}$} & -1.4 & Ferulic acid \\
\hline 8 & 36.84 & 449.1089 & $151.0036 / 285.0405$ & $\mathrm{C}_{21} \mathrm{H}_{22} \mathrm{O}_{11}$ & {$[\mathrm{M}-\mathrm{H}]^{-}$} & 0.1 & Neoastilbin \\
\hline 9 & 38.09 & 449.1099 & $151.0040 / 285.0413$ & $\mathrm{C}_{21} \mathrm{H}_{22} \mathrm{O}_{11}$ & {$[\mathrm{M}-\mathrm{H}]^{-}$} & -2.3 & Astilbin \\
\hline 10 & 40.67 & 449.1095 & $151.0037 / 285.0410$ & $\mathrm{C}_{21} \mathrm{H}_{22} \mathrm{O}_{11}$ & {$[\mathrm{M}-\mathrm{H}]^{-}$} & -1.3 & Neoisoastilbin \\
\hline 11 & 41.50 & 449.1094 & $151.0037 / 285.0408$ & $\mathrm{C}_{21} \mathrm{H}_{22} \mathrm{O}_{11}$ & {$[\mathrm{M}-\mathrm{H}]^{-}$} & -0.9 & Isoastilbin \\
\hline 12 & 43.45 & 433.1147 & $180.0068 / 269.0463$ & $\mathrm{C}_{21} \mathrm{H}_{22} \mathrm{O}_{10}$ & {$[\mathrm{M}-\mathrm{H}]^{-}$} & -1.6 & Engeletin \\
\hline 13 & 47.33 & 433.1137 & $180.0059 / 269.0448$ & $\mathrm{C}_{21} \mathrm{H}_{22} \mathrm{O}_{10}$ & {$[\mathrm{M}-\mathrm{H}]^{-}$} & -0.4 & Isoengelitin \\
\hline 14 & 49.31 & 137.0245 & 93.0354 & $\mathrm{C}_{7} \mathrm{H}_{6} \mathrm{O}_{3}$ & {$[\mathrm{M}-\mathrm{H}]^{-}$} & -0.5 & Salicylic acid \\
\hline 15 & 55.45 & 285.0409 & $133.0297 / 151.0033$ & $\mathrm{C}_{15} \mathrm{H}_{10} \mathrm{O}_{6}$ & {$[\mathrm{M}-\mathrm{H}]^{-}$} & -1.7 & Luteolin \\
\hline 16 & 56.15 & 313.0368 & 298.0126 & $\mathrm{C}_{16} \mathrm{H}_{10} \mathrm{O}_{7}$ & {$[\mathrm{M}-\mathrm{H}]^{-}$} & -4.4 & Wedelolactone \\
\hline 17 & 59.00 & 503.3381 & $389.2861 / 437.3066$ & $\mathrm{C}_{30} \mathrm{H}_{48} \mathrm{O}_{6}$ & {$[\mathrm{M}-\mathrm{H}]^{-}$} & -0.6 & Madecassic-acid \\
\hline 18 & 60.20 & 487.3431 & $379.3034 / 409.3156$ & $\mathrm{C}_{30} \mathrm{H}_{48} \mathrm{O}_{5}$ & {$[\mathrm{M}-\mathrm{H}]^{-}$} & -0.4 & Asiatic acid \\
\hline
\end{tabular}


In this study, we used a SHR model to assess the effects of LFG on attenuating blood pressure. Our data showed that LFG could significantly reduce blood pressure and increase serum NO content in SHRs compared with the model group. LFG ameliorated pathological changes such as cardiac hypertrophy and interstitial inflammation.

Although the animal experimental results showed that LFG could exert an antihypertensive effect in SHR, the active compounds and underlying molecular mechanisms are not clear. In the present study, a network pharmacology approach was applied to identify the active compounds, corresponding targets, and pharmacological mechanisms of LFG antihypertensive effect. Based on the results of public databases searching, 53 candidate compounds were collected from LFG, which were linked to 765 potential targets. A total of 828 hypertension associated targets were retrieved. The potential targets of antihypertensive effect were found by comparing LFG genes with hypertension genes, and 12 key targets were obtained after screening. After pathway enrichment of 12 key targets, 37 components and 34 pathways were found, among which the top 10 pathways were Bladder cancer, VEGF signaling pathway, Rap1 signaling pathway, Estrogen signaling pathway, HIF-1 signaling pathway, Oxytocin signaling pathway, PI3K-AKT signaling pathway, Pancreatic cancer, Proteoglycans in cancer, and Prolactin signaling pathway.

Twelve key genes were validated by RT-qPCR and western blot, and the results showed that LFG could upregulate the mRNA and protein expressions of NOS3 and SRC in thoracic aorta. NOS3 is mainly expressed in endothelial cells. Due to its vasodilator, antioxidant and antiproliferative properties, NO produced by NOS3 has become the main vascular protective agent [38]. It was reported that demethylasterriquinone b1 induced AKT activation may stimulate the expression and activity of NOS3 and inhibit the expression of p22phox subunit of NADPH oxidase from reducing oxidative stress and subsequently improve vascular endothelial dysfunction [39]. SRC tyrosine protein kinase is a non-receptor protein tyrosine kinase. It plays an important role in regulating cell differentiation, proliferation, and transformation, and also plays an important biological role in diseases such as hypertension and tumor [40,41]. It was reported that SRC was involved in the production of $\mathrm{NO}$ and prostaglini2 (PGI2) induced by VEGF, suggesting that SRC was involved in reducing vascular tension, relaxing blood vessels, and lowering blood pressure of VEGF in the vascular endothelium [42].

VEGF is a key protein regulator of angiogenesis under physiological and pathological conditions, and it may be important for vascular protection mechanism in hypertension [43]. Epidermal growth factor (EGF) is produced in different tissues and exerts stimulatory effects on cell growth, proliferation and survival. Vascular remodeling is caused by increased smooth muscle proliferation and may be due to an increase in the responsiveness of vascular cells to EGF [44]. EGF binds to its receptor (EGFR), which was identified as a plasma membrane protein tyrosine kinase in 1980 [45]. It was suggested that EGFR signaling is enhanced in various animal models of hypertension [46]. Prostaglandin G/H synthase 2 (PTGS2) also named Cyclooxygenase-2 (COX-2) is important in pathological processes such as inflammation. Hypertension is associated with augmented vascular COX-2 expression and COX-2-derived prostanoids [47]. Nerve growth factor (NGF) belongs to the neurotrophin family and plays an essential role in neuronal development, survival, and differentiation. Elevated NGF may be involved in developing hypertension in SHR [48]. Mitogen-activated protein kinase 1(MAPK1) also named Extracellular signal-regulated kinase 2 (ERK2) plays an essential role in the MAPK/ERK cascade. Depending on the cellular context, the MAPK/ERK cascade mediates diverse biological functions such as cell growth, adhesion, survival and differentiation through the regulation of transcription, translation, cytoskeletal rearrangements. A study reported that Bu-Shen-Jiang-Ya decoction (BSJYD) treatment decreased blood pressure and heart rate efficiently and reversed ventricular remodeling of SHR, and the mechanisms were possibly associated with the suppressive effect of BSJYD on the EKR signaling pathway [49]. C-C motif chemokine 2 (CCL2) also named Monocyte chemotactic protein 1 (MCP-1) is one of the chemotactic factors produced by damaged endothelial cells during the development of atherosclerosis. MCP-1 through the activation of CCR2 can induce migration and attachment of monocytes/macrophages, lymphocytes, endothelial cells and vascular smooth muscle cells [50]. Tyrosine hydroxylase (TH), a key enzyme in the catecholamine synthetic pathway, is increased in the adrenal medulla of SHR [51]. Neuropeptide Y (NPY) is a 36-amino acid peptide neurotransmitter, released from postganglionic sympathetic perivascular neurons [52]. Alternations of NPY release may play a role in the pathophysiology of at least some forms of hypertension [53]. Estrogen receptor 1 (ESR1) is a nuclear hormone receptor. The steroid hormones and their receptors are involved in regulating eukaryotic gene expression and affect cellular proliferation and differentiation in target tissues. It was demonstrated that ESR1 plays an important role in pulmonary arterial hypertension [54]. Taken together, the above 12 key targets were closely related to hypertension, among which the levels of NOS3 and SRC were restored by LFG.

Pathway enrichment results showed that the PI3KAKT signaling pathway was closely related to the 
expression of NOS3 and SRC. To verify this result, western blot was used to detect the key proteins (PI3K, $\mathrm{AKT}$, and $\mathrm{p}-\mathrm{AKT}$ ) of the PI3K-AKT signaling pathway. The results showed that LFG significantly increased the protein expression levels of PI3K and p-AKT in SHRs, suggesting that LFG may play a role through the PI3KAKT signaling pathway. The PI3K-AKT signaling pathway is activated by various types of cellular stimuli or toxic insults and regulates fundamental cellular functions such as transcription, translation, proliferation, growth, and survival. PI3K catalyzes the production of phosphatidylinositol-3,4,5-triphosphate (PIP3) on the cell membrane. In turn, PIP3 serves as a second messenger to help activate AKT. Once activated, AKT can control key cellular processes by phosphorylating substrates in apoptosis, protein synthesis, metabolism, and cell cycle. It has been reported that the AKT activity of blood vessels characterized by Ser473 phosphorylation is downregulated in a number of hypertensive rat models, including SHRs [55]. Importantly, phosphorylation of AKT at Ser473 contributes to NOS3 activation [56]. SRC regulates the activity of PI3K-AKT signaling, and contributes to improving endothelial dysfunction [57]. Taken together, the mechanism of LFG exerting antihypertensive effect was showed in Fig. 11. LFG can lower the blood pressure of SHRs, which might be attributed to upregulating SRC expression level, activating the
PI3K-AKT-NOS3 signaling pathway to further increase the serum NO level for promoting vasodilation.

Molecular docking studies further supported that p-hydroxybenzoic acid, cedar acid, shikimic acid, salicylic acid, nicotinic acid, linalool, and histidine can bind well with NOS3, SRC, PI3K, and AKT. These compounds were the potential active ingredients for LFG antihypertensive effect. p-Hydroxybenzoic acid can be isolated from a variety of plants, such as oil palm, Vitex negundo and virgin olive oil [58-60]. It was reported that p-hydroxybenzoic acid possessed a variety of biological properties, including anti-inflammatory, antioxidant cardio protective and vasodilatory effects [61]. p-Hydroxybenzoic acid causes a decrease in blood pressure and dilatation of the aortic rings. The biological principles were to act directly on the vascular smooth muscle to cause vasodilatation, and indirectly by stimulating the release of $\mathrm{NO}$ from the vascular endothelium to promote the vasodilator activity of the compound [62]. Cedar acid is one of the phenolic compounds widely found in olives, dates, spices, pumpkin, grapes, acai palm and other plants [63]. In addition, it exhibits multi-pharmacological properties such as antihypertensive, antioxidant, anti-inflammatory, and hepatoprotective activities $[64,65]$. Cedar acid showed antihypertensive activity in hypertensive rats induced by $\mathrm{N}$-nitro-L-arginine methyl ester (L-NAME). It was evidenced that Cedar acid treatment might reduce the blood

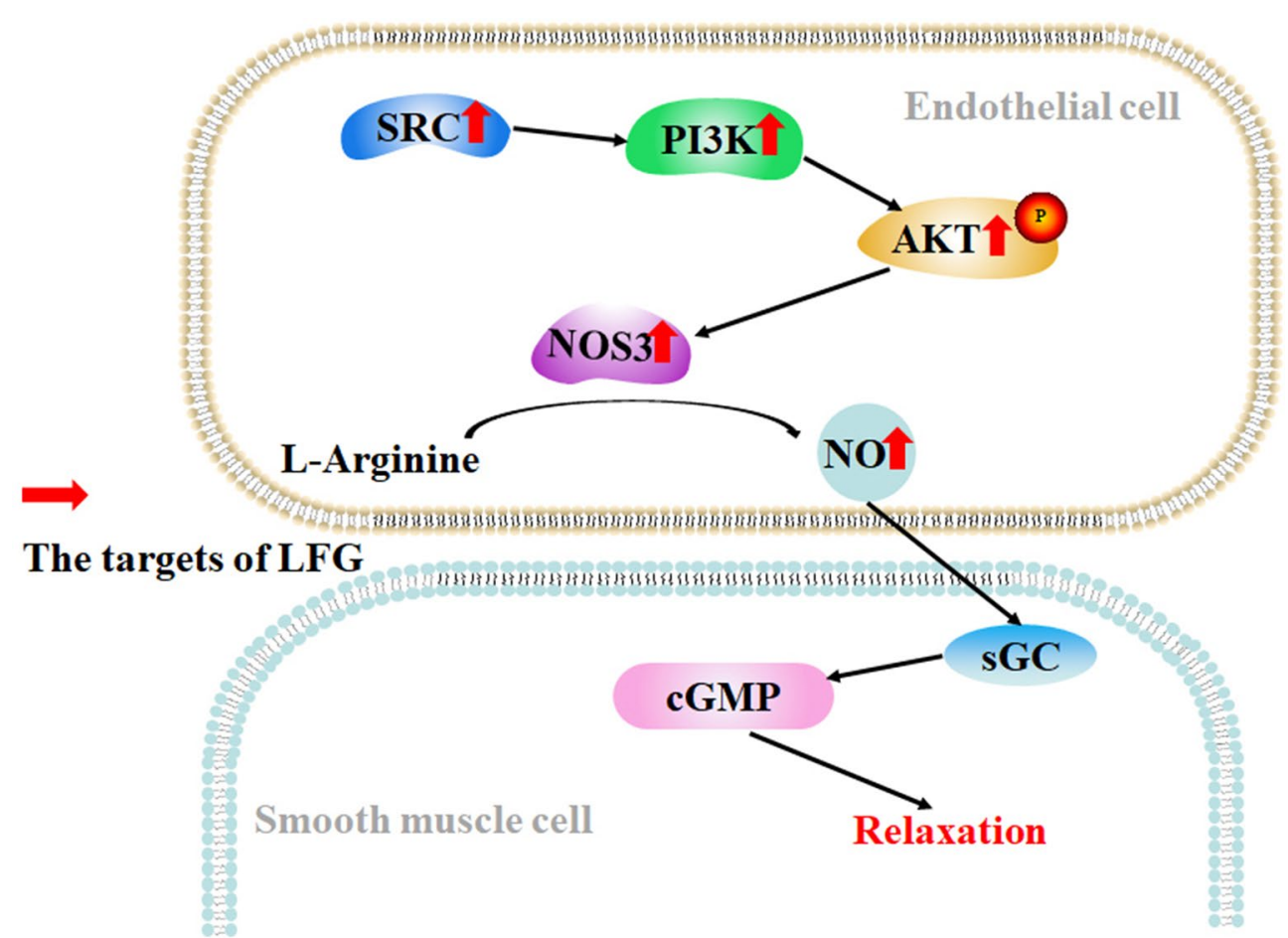

Fig. 11 LFG antihypertensive mechanism 
pressure, lipid peroxides, and increase $\mathrm{NO}$ availability and antioxidant levels in blood samples of rats [66]. Shikimic acid originally extracted from Chinese star anise, exerts diverse pharmacological actions such as analgesic, anti-inflammatory, and antioxidant effects [67-69]. Previous studies indicated that Shikimic acid inhibited inflammatory events including the production of $\mathrm{NO}$ and the expression of pro-inflammatory cytokines [70]. Chemically, Salicylic acid is 2-hydroxybenzoic acid or orthohydrobenzoic acid. Sources of Salicylic acid include willow bark, sweet birch, and wintergreen leaves, and it can also be synthesized artificially [71]. Salicylic acid, the Xinjiang red raspberry fruit extract, moderately reduced SHR blood pressure, the effect may be related to increasing serum NO, SOD activity and T-AOC levels, enhanced NOS3 mRNA expression [72]. Niacin, also known as vitamin B3, illustrates the many functions of water-soluble vitamins. Niacin has been widely used in the treatment of dyslipidemia and atherosclerotic coronary heart disease [73]. In addition to its lipid-lowering effect, Niacin also has powerful antioxidant and anti-inflammatory properties [74]. Cho etc. showed that long-term Niacin administration improves hypertension, proteinuria and attenuates the accumulation of lipids in the remnant kidneys of animals with CRF induced by subtotal nephrectomy [75]. Linalool is a monoterpene and is generally consideredthe main component of essential oils obtained from aromatic plant species [76]. Linalool showed a wide range of biological activities including anti-inflammatory, anti-cancer, anti-hyperlipidemic, anti-microbial effects [77]. Data showed that the use of Linalool for sub-chronic treatment could reduce the development of hypertension in SHRs, reduce cardiac hypertrophy, increase IL-10 anti-inflammatory cytokine, and improve vasodilatory function and decreasing vasoconstriction [78]. Histidine is an essential amino acid in humans and other mammals which exhibits antioxidant and anti-inflammatory properties [79]. In dietary intervention and evaluation experiment, the relationship between the intake of specific amino acids and blood pressure levels was analyzed, and the results demonstrated that intakes of Methionine and Alanine were positively correlated with higher blood pressure, while intakes of Threonine and Histidine had inverse associations [80]. It has been proved that L-histidine has an antihypertensive effect after oral administration in SHRs. These effects may be mediated by central histamine $\mathrm{H} 3$ receptor, which seems to be related to an increase in NO in the rostral ventrolateral medulla [81].

After comparing the components with the reference standard and LFG by UPLC-MS/MS, it can be determined that p-hydroxybenzoic acid, shikimic acid, salicylic acid, and nicotinic acid were presented in LFG. In addition, the contents of above 4 compounds in
LFG were relatively high. Therefore, it is possible that p-hydroxybenzoic acid, shikimic acid, salicylic acid, and nicotinic acid contribute to the therapeutic effect of LFG. Cell viability assay in vitro suggested that nicotinic acid have substantial protective effects against the reduction in endothelial cell viability caused by $\mathrm{H}_{2} \mathrm{O}_{2}$ treatment, and it could promote the release of NO from HUVEC. In conclusion, nicotinic acid might be the basis of the antihypertensive effect of LFG.

\section{Conclusions}

LFG can lower the blood pressure of SHRs, which might be attributed to the upregulation of SRC and activation of the PI3K-AKT-NOS3 signaling pathway, which further increases the serum NO level, thereby promoting vasodilation. Nicotinic acid might be the underlying active compound for LFG antihypertensive effect.

\section{Abbreviations}

AKT: Protein kinase B; ANG-II: Angiotensin II; BATMAN-TCM: Bioinformatics Analysis Tool for Molecular Mechanism of Traditional Chinese Medicine; BCA: Bicinchoninic acid; BSA: Bovine Serum Albumin; CCL2: C-C motif chemokine 2; COX-2: Cyclooxygenase-2; DAVID: Database for Annotation, Visualization and Integrated Discovery; EGF: Epidermal growth factor; EGFR: Epidermal growth factor receptor; ERK: Mitogen-activated protein kinase; ESR1: Estrogen receptor 1; ET-1: Endothelin 1; H\&E staining: Hematoxylin-eosin staining; $\mathrm{H}_{2} \mathrm{O}_{2}$ : hydrogen peroxide; HUVEC: human umbilical vein endothelial cells; KEGG: Kyoto Encyclopedia of Genes and Genomes; LFG: Lei-gong-gen formula granule; MAPK1: Mitogen-activated protein kinase; MCP-1: Monocyte chemotactic protein 1; NGF: Nerve growth factor; NO: Nitric oxide; NOS3: Endothelial nitric oxide synthase; NPY: neuropeptide Y; OB: Oral bioavailability; PDB: Protein Data Bank; PI3K: Phosphatidylinositol 3 kinase; PTGS2: Prostaglandin G/H synthase 2; SHR: Spontaneously hypertensive rats; SRC: Proto-oncogene tyrosine-protein kinase SRC; STRING: Search Tool for the Retrieval of Interacting Genes/Proteins; TCMID: Traditional Chinese Medicines Integrated Database; TCMSP:Traditional Chinese Medicine Systems Pharmacology Database and Analysis Platform; TH: Tyrosine hydroxylase; T-HOD: Text-mined Hypertension, Obesity and Diabetes candidate gene database; UPLC-QTOF/MS: Ultra performance liquid chromatography/quadrupole time-of-flight mass spectrometry; VEGFA: Vascular endothelial growth factor $\mathrm{A}$.

\section{Supplementary Information}

The online version contains supplementary material available at https://doi. org/10.1186/s13020-021-00507-1.

Additional file 1: Table S1. The contents of 14 compounds obtained from literatures. Table S2. The 828 significant genes associated with hypertension. Table S3. Docking results of 10 active ingredients and NOS3. Table S4. Docking results of 10 active ingredients and SRC.

Table S5. Docking results of 10 active ingredients and PI3K. Table S6. Docking results of 10 active ingredients and AKT.

Additional file 2: Figures S1-S18. The mass spectrum comparison of components in LFG with the reference standard.

Acknowledgements

The authors thank Yanying Liu and Zhiping Chen for technical assistance and Kai Wei for editing. 


\section{Authors' contributions}

$H G, D Z, Z S$ contributed to designing the work. QL, TL and WC wrote the manuscript, analyzed and interpreted of data. QL, TL, SH, XL, WZ, YL, QZ, XC and $\mathrm{YH}$ performed the experiments. $\mathrm{HG}$ provided reagents/materials/analysis tools. All authors read and approved the final version.

\section{Funding}

This work was supported by Guangxi Natural Science Foundation (2020GXNSFAA259030, 2018GXNSFAA138096); Guangxi Science and Technology Projects (GUIKEGONG 1598013-8); Open Project of Guangxi Key Laboratory of Regenerative Medicine (GUIZAIZHONGKAI 201903), Guangxi First-class Discipline Project for Pharmaceutical Sciences (GXFCDP-PS-2018); Natural Science Foundation of Guangxi University of Chinese Medicine (2019QN004).

\section{Availability of data and materials}

The datasets used and/or analyzed during the current study are available from the corresponding author on reasonable request.

\section{Declarations}

\section{Ethics approval and consent to participate}

The experimental procedures were approved by the Institutional Animal Ethics Committee (IAEC), Guangxi Medical University.

\section{Consent for publication}

Not applicable.

\section{Competing interests}

The authors declare that they have no competing interests.

\section{Author details}

${ }^{1}$ Guangxi Key Laboratory of Bioactive Molecules Research and Evaluation \& College of Pharmacy, Guangxi Medical University, 22 Shuangyong Road, Nanning 530021, China. ${ }^{2}$ Key Laboratory of Longevity and Aging-related Diseases of Chinese Ministry of Education \& Center for Translational Medicine, School of preclinical medicine, Guangxi Medical University, Nanning 530021, Guangxi, China. ${ }^{3}$ School of preclinical medicine, Guangxi University of Chinese Medicine, 179 Mingxiu Dong Road, Nanning 530001, China. ${ }^{4}$ Guangxi Institute for Food and Drug Control, 9 Qinghu Road, Nanning 530021, China. ${ }^{5}$ Guangxi Key Laboratory of Regenerative Medicine, Guangxi Medical University, Nan-

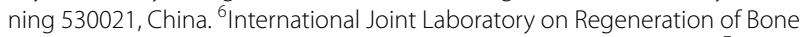
and Soft Tissues, Guangxi Medical University, Guangxi 530021, China. ${ }^{7}$ College of Pharmacy, Guangxi University of Chinese Medicine, 179 Mingxiu Dong Road, Nanning 530001, China. ${ }^{8}$ The First Affiliated Hospital, Guangxi Medical University, 6 Shuangyong Road, Nanning 530021, China.

\section{Received: 17 February 2021 Accepted: 17 September 2021}

Published online: 09 October 2021

\section{References}

1. Wang H, Liu C, Zhai J, Shang H. Niuhuang Jiangya Preparation (a traditional Chinese patent medicine) for essential hypertension: a systematic review. Complement Ther Med. 2017:31:90-9.

2. Li Y, Yang L, Wang L, Zhang M, Huang Z, Deng Q, et al. Burden of hypertension in China: a nationally representative survey of 174,621 adults. Int J Cardiol. 2017;227:516-23.

3. Wolf-Maier K, Cooper RS, Banegas JR, Giampaoli S, Hense HW, Joffres M, et al. Hypertension prevalence and blood pressure levels in 6 European countries, Canada, and the United States. JAMA. 2003;289(18):2363-9.

4. Xiong $X$, Wang $P$, Li X, Zhang Y. Shenqi pill, a traditional Chinese herbal formula, for the treatment of hypertension: a systematic review. Complement Ther Med. 2015;23(3):484-93.

5. Wu W, Yang S, Liu P, Yin L, Gong Q, Zhu W. Systems pharmacology-based strategy to investigate pharmacological mechanisms of radix puerariae for treatment of hypertension. Front Pharmacol. 2020;11:345.

6. Ye XT, Zhang BX, Wang HH, He SB, Zhang XH, Wang Y. Study on mechanism for anti-hypertension efficacy of Eucommiae Cortex through assistant analysis systems for acting mechanisms of traditional Chinese medicine. China J Chin Materia Medica. 2015;40(19):3718-22.

7. Lan TJ, Liang WP, Feng QY, Yun CX, Guo HW. Multi-index integrated evaluation method optimizes water-extraction of Leigong Antihypertensive Granules. J Chin Med Mater. 2018;9:2171-4.

8. Xin RB, Meng GY, He L, Lu J, Huang WY, Ye LL, et al. Sampling survey of hypertension in Zhuang nationality in Tiandong county. Guangxi Med J. 2011;33(8):963-5.

9. Razali NNM, Ng CT, Fong LY. Cardiovascular protective effects of centella asiatica and its triterpenes: a review. Planta Med. 2019;85(16):1203-15.

10. Astutik FEF, Fauzia Zuhroh D, Rizqi Lazuardi Ramadhan M. The effect of gotu kola (Centella asiatica L.) tea on blood pressure of hypertension. Enferm Clin. 2021;31(Suppl 2):195-S8.

11. Bunbupha S, Prachaney P, Kukongviriyapan U, Kukongviriyapan V, Welbat JU, Pakdeechote P. Asiatic acid alleviates cardiovascular remodelling in rats with L-NAME-induced hypertension. Clin Exp Pharmacol Physiol. 2015:42(11):1189-97.

12. Liao MY, Chuang CY, Hsieh MJ, Chou YE, Lin CW, Chen WR, et al. Antimetastatic effects of Eclipta prostrata extract on oral cancer cells. Environ Toxicol. 2018;33(9):923-30.

13. Chung IM, Rajakumar G, Lee JH, Kim SH, Thiruvengadam M. Ethnopharmacological uses, phytochemistry, biological activities, and biotechnological applications of Eclipta prostrata. Appl Microbiol Biotechnol. 2017; 101(13):5247-57

14. Sa F, Gao JL, Fung KP, Zheng Y, Lee SM, Wang YT. Anti-proliferative and pro-apoptotic effect of Smilax glabra Roxb. extract on hepatoma cell lines. Chem Biol Interact. 2008;171(1):1-14.

15. Cai Y, Tu J, Pan S, Jiang J, Shou Q, Ling Y, et al. Medicinal effect and its JP2/RyR2-based mechanism of Smilax glabra flavonoids on angiotensin II-induced hypertrophy model of cardiomyocytes. J Ethnopharmacol. 2015;169:435-40.

16. Wermuth CG. Multitargeted drugs: the end of the "one-target-onedisease". philosophy? Drug Discov Today. 2004;9(19):826-7.

17. Li S, Zhang B. Traditional Chinese medicine network pharmacology: theory, methodology and application. Chin J Nat Med. 2013;11(2):110-20.

18. Li H, Zhao L, Zhang B, Jiang Y, Wang X, Guo Y, et al. A network pharmacology approach to determine active compounds and action mechanisms of ge-gen-qin-lian decoction for treatment of type 2 diabetes. Evid Based Complement Alternat Med. 2014;2014:495840.

19. Li S, Chen Y, Ding Q, Dai J, Duan X, Hu Y, et al. Network pharmacology evaluation method guidance - Draft. World J Tradit Chin Med. 2021;7(1):146-54.

20. Tao W, Xu X, Wang X, Li B, Wang Y, Li Y, et al. Network pharmacologybased prediction of the active ingredients and potential targets of Chinese herbal Radix Curcumae formula for application to cardiovascular disease. J Ethnopharmacol. 2013;145(1):1-10.

21. Lan T, Chang M, Li Q, Liang W, Yun C, Guo H. Optimization of formation process for leigong antihypertensive granules by central composite design-respones surface methodology based on CRITIC Weighted Evaluation. J Chin Med Mater. 2019;42(6):1356-9.

22. Lan T, Li Q, Chang M, Yin C, Zhu D, Wu Z, et al. Lei-gong-gen formula granule attenuates hyperlipidemia in rats via CGMP-PKG signaling pathway. J Ethnopharmacol. 2020;260:112989.

23. Giudicelli JF, Freslon JL, Glasson S, Richer C. Captopril and hypertension development in the SHR. Clin Exp Hypertens. 1980;2(6):1083-96.

24. Ru J, Li P, Wang J, Zhou W, Li B, Huang C, et al. TCMSP: a database of systems pharmacology for drug discovery from herbal medicines. J Cheminform. 2014;6:13.

25. Xue R, Fang Z, Zhang M, Yi Z, Wen C, Shi T. TCMID: Traditional Chinese Medicine integrative database for herb molecular mechanism analysis. Nucleic Acids Res. 2013;41(Database issue):D1089-95.

26. Liu Z, Guo F, Wang Y, Li C, Zhang X, Li H, et al. BATMAN-TCM: a Bioinformatics Analysis Tool for Molecular mechANism of Traditional Chinese Medicine. Sci Rep. 2016;6:21146.

27. Xu X, Zhang W, Huang C, Li Y, Yu H, Wang Y, et al. A novel chemometric method for the prediction of human oral bioavailability. Int J Mol Sci. 2012;13(6):6964-82.

28. Gong J, Cai C, Liu X, Ku X, Jiang H, Gao D, et al. ChemMapper: a versatile web server for exploring pharmacology and chemical structure 
association based on molecular 3D similarity method. Bioinformatics. 2013;29(14):1827-9.

29. Dai HJ, Wu JC, Tsai RT, Pan WH, Hsu WL. T-HOD: a literature-based candidate gene database for hypertension, obesity and diabetes. Database. 2013;2013:bas061.

30. Shannon P, Markiel A, Ozier O, Baliga NS, Wang JT, Ramage D, et al. Cytoscape: a software environment for integrated models of biomolecular interaction networks. Genome Res. 2003;13(11):2498-504.

31. Szklarczyk D, Gable AL, Lyon D, Junge A, Wyder S, Huerta-Cepas J, et al. STRING v11: protein-protein association networks with increased coverage, supporting functional discovery in genome-wide experimental datasets. Nucleic Acids Res. 2019;47(D1):D607-D13.

32. Huang da W, Sherman BT, Lempicki RA. Systematic and integrative analysis of large gene lists using DAVID bioinformatics resources. Nat Protoc. 2009;4(1):44-57.

33. Livak KJ, Schmittgen TD. Analysis of relative gene expression data using real-time quantitative PCR and the 2(-Delta Delta C(T)) Method. Methods. 2001;25(4):402-8.

34. Arif M, Sadayappan S, Becker RC, Martin LJ, Urbina EM. Epigenetic modification: a regulatory mechanism in essential hypertension. Hypertens Res. 2019:42(8):1099-113.

35. Makani H, Bangalore S, Romero J, Htyte N, Berrios RS, Makwana H, et al. Peripheral edema associated with calcium channel blockers: incidence and withdrawal rate-a meta-analysis of randomized trials. J Hypertens. 2011;29(7):1270-80

36. Raebel MA. Hyperkalemia associated with use of angiotensin-converting enzyme inhibitors and angiotensin receptor blockers. Cardiovasc Ther. 2012;30(3):e156-66.

37. Xiong $X$, Yang $X$, Liu $Y$, Zhang $Y$, Wang $P$, Wang J. Chinese herbal formulas for treating hypertension in traditional Chinese medicine: perspective of modern science. Hypertens Res. 2013;36(7):570-9.

38. Banquet S, Delannoy E, Agouni A, Dessy C, Lacomme S, Hubert F, et al. Role of G(i/o)-Src kinase-PI3K/Akt pathway and caveolin-1 in beta(2)adrenoceptor coupling to endothelial NO synthase in mouse pulmonary artery. Cell Signal. 2011;23(7):1136-43.

39. Shah DI, Singh M. Effect of demethylasterriquinone b1 in hypertension associated vascular endothelial dysfunction. Int J Cardiol. 2007;120(3):317-24

40. Frame MC. Src in cancer: deregulation and consequences for cell behaviour. Biochim Biophys Acta. 2002;1602(2):114-30.

41. Paravicini TM, Montezano AC, Yusuf H, Touyz RM. Activation of vascular p38MAPK by mechanical stretch is independent of $\mathrm{c}-\mathrm{Src}$ and NADPH oxidase: influence of hypertension and angiotensin II. J Am Soc Hypertens. 2012;6(3):169-78.

42. He H, Venema VJ, Gu X, Venema RC, Marrero MB, Caldwell RB. Vascular endothelial growth factor signals endothelial cell production of nitric oxide and prostacyclin through flk-1/KDR activation of c-Src. J Biol Chem. 1999;274(35):25130-5.

43. Gu JW, Fortepiani LA, Reckelhoff JF, Adair TH, Wang J, Hall JE. Increased expression of vascular endothelial growth factor and capillary density in hearts of spontaneously hypertensive rats. Microcirculation. 2004;11(8):689-97.

44. Dorrance AM, Osborn HL, Grekin R, Webb RC. Spironolactone reduces cerebral infarct size and EGF-receptor mRNA in stroke-prone rats. Am J Physiol Regul Integr Comp Physiol. 2001;281(3):R944-50.

45. Ushiro H, Cohen S. Identification of phosphotyrosine as a product of epidermal growth factor-activated protein kinase in A-431 cell membranes. J Biol Chem. 1980;255(18):8363-5.

46. Beltowski J, Lowicka E. EGF receptor as a drug target in arterial hypertension. Mini Rev Med Chem. 2009:9(5):526-38.

47. Martin A, Perez-Giron JV, Hernanz R, Palacios R, Briones AM, Fortuno $A$, et al. Peroxisome proliferator-activated receptor-gamma activation reduces cyclooxygenase-2 expression in vascular smooth muscle cells from hypertensive rats by interfering with oxidative stress. J Hypertens. 2012;30(2):315-26.

48. Clemow DB, Spitsbergen JM, McCarty R, Steers WD, Tuttle JB. Arterial nerve growth factor (NGF) mRNA, protein, and vascular smooth muscle cell NGF secretion in hypertensive and hyperactive rats. Exp Cell Res. 1998:244(1):196-205.

49. Xiong X, Yang X, Duan L, Liu W, Zhang Y, Liu Y, et al. Traditional Chinese medicine suppresses left ventricular hypertrophy by targeting extracellular signal-regulated kinases signaling pathway in spontaneously hypertensive rats. Sci Rep. 2017;7:42965.

50. Mukai Y, Sato S. Polyphenol-containing azuki bean (Vigna angularis) seed coats attenuate vascular oxidative stress and inflammation in spontaneously hypertensive rats. J Nutr Biochem. 2011;22(1):16-21.

51. Kumai T, Takeba Y, Matsumoto N, Nakaya S, Tsuzuki Y, Yanagida Y, et al. Fasudil attenuates sympathetic nervous activity in the adrenal medulla of spontaneously hypertensive rats. Life Sci. 2007;81(15):1193-8.

52. Crnkovic S, Egemnazarov B, Jain P, Seay U, Gattinger N, Marsh LM, et al. $N P Y / Y(1)$ receptor-mediated vasoconstrictory and proliferative effects in pulmonary hypertension. Br J Pharmacol. 2014;171(16):3895-907.

53. Michel MC, Rascher W. Neuropeptide Y: a possible role in hypertension? J Hypertens. 1995;13(4):385-95.

54. Rajkumar R, Konishi K, Richards TJ, Ishizawar DC, Wiechert AC, Kaminski N, et al. Genomewide RNA expression profiling in lung identifies distinct signatures in idiopathic pulmonary arterial hypertension and secondary pulmonary hypertension. Am J Physiol Heart Circ Physiol. 2010;298(4):H1235-48.

55. Xing W, Yan W, Liu P, Ji L, Li Y, Sun L, et al. A novel mechanism for vascular insulin resistance in normotensive young SHRs: hypoadiponectinemia and resultant APPL1 downregulation. Hypertension. 2013;61(5):1028-35.

56. Yamamoto E, Yamashita T, Tanaka T, Kataoka K, Tokutomi Y, Lai ZF, et al. Pravastatin enhances beneficial effects of olmesartan on vascular injury of salt-sensitive hypertensive rats, via pleiotropic effects. Arterioscler Thromb Vasc Biol. 2007;27(3):556-63.

57. Nemoto S, Kobayashi T, Taguchi K, Matsumoto T, Kamata K. Losartan improves aortic endothelium-dependent relaxation via proline-rich tyrosine kinase 2/Src/Akt pathway in type 2 diabetic Goto-Kakizaki rats. Am J Physiol Heart Circ Physiol. 2011:301 (6):H2383-94.

58. Chong KP, Rossall S, Atong M. In vitro antimicrobial activity and fungitoxicity of syringic acid, caffeic acid and 4-hydroxybenzoic acid against ganoderma boninense. J Agric Sci. 2009;1:2.

59. Figueiredo-Gonzalez M, Reboredo-Rodriguez P, Gonzalez-Barreiro C, Simal-Gandara J, Valentao P, Carrasco-Pancorbo A, et al. Evaluation of the neuroprotective and antidiabetic potential of phenol-rich extracts from virgin olive oils by in vitro assays. Food Res Int. 2018;106:558-67.

60. Ling WC, Ahmad F, Mat Ali R. Luteolin and 4-Hydroxybenzoic Acid from the Leaves Vitex negundo. 2005.

61. Chaudhary J, Jain A, Manuja R, Sachdeva S. A comprehensive review on biological activities of p-hydroxy benzoic acid and its derivatives. Int J Pharm Sci Rev Res. 2013;22:2.

62. Leeya Y, Mulvany MJ, Queiroz EF, Marston A, Hostettmann K, Jansakul C. Hypotensive activity of an $\mathrm{n}$-butanol extract and their purified compounds from leaves of Phyllanthus acidus (L.) Skeels in rats. Eur J Pharmacol. 2010;649(1-3):301-13.

63. Srinivasulu C, Ramgopal M, Ramanjaneyulu G, Anuradha CM, Suresh Kumar C. Syringic acid (SA) A Review of Its Occurrence, Biosynthesis, Pharmacological and Industrial Importance. Biomed Pharmacother. 2018;108:547-57.

64. Jalili T, Carlstrom J, Kim S, Freeman D, Jin H, Wu TC, et al. Quercetinsupplemented diets lower blood pressure and attenuate cardiac hypertrophy in rats with aortic constriction. J Cardiovasc Pharmacol. 2006:47(4):531-41.

65. Kiran p, Denn.i M, Daniel M. Antidiabetic Principles, Phospholipids And Fixed Oil of Kodo Millet (Paspalum scrobiculatum Linn.). Indian Journal of Applied Research. 2011:4:13-5.

66. Kumar S, Prahalathan P, Raja B. Syringic acid ameliorates (L)-NAMEinduced hypertension by reducing oxidative stress. Naunyn Schmiedebergs Arch Pharmacol. 2012;385(12):1175-84.

67. Benmalek Y, Yahia OA, Belkebir A, Fardeau ML. Anti-microbial and antioxidant activities of Illicium verum, Crataegus oxyacantha ssp monogyna and Allium cepa red and white varieties. Bioengineered. 2013;4(4):244-8.

68. Nakamura T, Okuyama E, Yamazaki M. Neurotropic components from star anise (Illicium verum Hook. fil.). Chem Pharm Bull (Tokyo). 1996;44(10):1908-14.

69. Thring TS, Hili P, Naughton DP. Anti-collagenase, anti-elastase and antioxidant activities of extracts from 21 plants. BMC Complement Altern Med. 2009;9:27.

70. Rabelo TK, Guimaraes AG, Oliveira MA, Gasparotto J, Serafini MR, de Souza Araujo AA, et al. Shikimic acid inhibits LPS-induced cellular 
pro-inflammatory cytokines and attenuates mechanical hyperalgesia in mice. Int Immunopharmacol. 2016;39:97-105.

71. Arif T. Salicylic acid as a peeling agent: a comprehensive review. Clin Cosmet Investig Dermatol. 2015;8:455-61.

72. Han J, He GS, Liu JW, Peter A, Chen PP. Anti-oxidant Effects of Xinjiang Red Raspberry Fruit Extracts in Spontaneously Hypertensive Rats. Chinese Journal of Hypertension. 2009;17(8):695-9.

73. Meyers CD, Kamanna VS, Kashyap ML. Niacin therapy in atherosclerosis. Curr Opin Lipidol. 2004;15(6):659-65.

74. Cho KH, Kim HJ, Rodriguez-Iturbe B, Vaziri ND. Niacin ameliorates oxidative stress, inflammation, proteinuria, and hypertension in rats with chronic renal failure. Am J Physiol Renal Physiol. 2009;297(1):F106-13.

75. Cho KH, Kim HJ, Kamanna VS, Vaziri ND. Niacin improves renal lipid metabolism and slows progression in chronic kidney disease. Biochim Biophys Acta. 2010;1800(1):6-15.

76. Linck VM, da Silva AL, Figueiro M, Piato AL, Herrmann AP, Dupont Birck $\mathrm{F}$, et al. Inhaled linalool-induced sedation in mice. Phytomedicine. 2009;16(4):303-7.

77. Pereira I, Severino P, Santos AC, Silva AM, Souto EB. Linalool bioactive properties and potential applicability in drug delivery systems. Colloids Surf B Biointerfaces. 2018;171:566-78.

78. Camargo SB, Simoes LO, Medeiros CFA, de Melo Jesus A, Fregoneze $J B$, Evangelista A, et al. Antihypertensive potential of linalool and linalool complexed with beta-cyclodextrin: Effects of subchronic treatment on blood pressure and vascular reactivity. Biochem Pharmacol. 2018;151:38-46.

79. Vera-Aviles M, Vantana E, Kardinasari E, Koh NL, Latunde-Dada GO. Protective Role of Histidine Supplementation Against Oxidative Stress Damage in the Management of Anemia of Chronic Kidney Disease. Pharmaceuticals (Basel). 2018;11:4.

80. Tuttle KR, Milton JE, Packard DP, Shuler LA, Short RA. Dietary amino acids and blood pressure: a cohort study of patients with cardiovascular disease. Am J Kidney Dis. 2012;59(6):803-9.

81. Toba H, Nakamori A, Tanaka Y, Yukiya R, Tatsuoka K, Narutaki M, et al. Oral L-histidine exerts antihypertensive effects via central histamine H3 receptors and decreases nitric oxide content in the rostral ventrolateral medulla in spontaneously hypertensive rats. Clin Exp Pharmacol Physiol. 2010;37(1):62-8.

\section{Publisher's Note}

Springer Nature remains neutral with regard to jurisdictional claims in published maps and institutional affiliations.
Ready to submit your research? Choose BMC and benefit from:

- fast, convenient online submission

- thorough peer review by experienced researchers in your field

- rapid publication on acceptance

- support for research data, including large and complex data types

- gold Open Access which fosters wider collaboration and increased citations

- maximum visibility for your research: over $100 \mathrm{M}$ website views per year

At BMC, research is always in progress.

Learn more biomedcentral.com/submissions 